\title{
El proceso de independencia del Perú y algunos episodios sobre su reconocimiento en el concierto de las naciones ${ }^{1}$
}

\author{
Recibido: 17/08/2021 \\ Aprobado: 16/11/2021
}

\author{
CARLOTA CASALINO SEN \\ Universidad Nacional Mayor de San Marcos (UNMSM) \\ ccasalinos@unmsm.edu.pe \\ https://orcid.org/0000-0002-3102-8925
}

\section{RESUMEN}

En este artículo se explica que la conformación del Gobierno del Perú y la búsqueda de su reconocimiento por los otros países se inició durante el proceso de la independencia. Para el logro de este objetivo, se nombró al primer encargado en la función de ministro de Estado y Relaciones Exteriores. Sin embargo, esta cartera ministerial no estuvo al margen de la inestabilidad política que caracterizó a todo el siglo XIX, razón por la cual se llegó a designar hasta dos ministros, en promedio, por año. En el artículo también se destaca el establecimiento de las relaciones formales con algunos países de la región, así como con España y el Vaticano. Asimismo, se desarrolla la participación del Perú en el Congreso de Panamá, como un primer intento de coordinación supranacional. En síntesis, en el artículo se trata de demostrar que el proceso de reconocimiento internacional del Perú comenzó desde el inicio de la independencia y que duró alrededor de cinco décadas debido al contexto interno y externo adverso.

Palabras clave: Perú, inserción en el concierto de las naciones, Congreso de Panamá, ministros de Relaciones Exteriores peruanos

\section{The process of independence of Peru and some episodes about its recognition in the concert of nations}

\begin{abstract}
This article explains that the formation of the government of Peru and the search for its recognition by other countries began during the process of independence. To achieve this objective, a Minister of State and Foreign Relations was appointed for the first time. However, this ministerial portfolio was not exempt from the political instability that characterized the entire nineteenth century, which is why up to two ministers, on average, were appointed per year. The article also highlights the establishment of formal relations with some countries of the region, as well as with Spain and the Vatican. Likewise, the participation of Peru in the Congress of Panama is examined, as a first attempt at supranational coordination. In summary, the article tries to demonstrate that the process of international recognition of Peru began from the beginning of the independence, and that it lasted around five decades due to the adverse internal and external context.
\end{abstract}

Keywords: Peru, insertion in the concert of nations, Congress of Panama, Peruvian Foreign Ministers

1 Este artículo forma parte del proyecto de investigación del GI HyCA registrado en el VRIP-UNMSM con código E21150092. Asimismo, se contó con el apoyo del Lic. Juan Marcos Martínez. 
El Perú, libre, fraternal y generoso es José Sánchez Carrión invitando por orden de Bolívar a la primera asamblea americana de Panamá; es Manuel Lorenzo Vidaurre planeando con fantasía exaltada el anfictionado del Nuevo Mundo; es José Gregorio Paz Soldán defendiendo con gallardía la teoría de la jurisdicción nacional y atendiendo al interés de América, en 1847; es José Fabio Melgar, protestando de la anexión de Santo Domingo a España; es Manuel Nicolás Corpancho llevando la adhesión peruana a México invadido por los ejércitos imperiales; es Juan Antonio Ribeyro convocando a la solidaridad frente a la agresión española de 1864; es José Antonio Barrenechea reconociendo la beligerancia e independencia de Cuba; y es, particular y gloriosamente, Toribio Pacheco, el jurista, el representativo sereno de nuestro derecho herido, y el defensor cálido y generoso del incoercible derecho de los débiles (Porras 1928b, 41).

C

uando la historiografía se refiere al proceso de independencia del Perú, suele empezar señalando que fue parte de un proceso político que tuvo una escala global (Sobrevilla 2021, Zuloaga 2021, Chust y Rosas 2017, Estenssoro 2021, entre otros). En efecto, los procesos políticos europeos tuvieron impacto en la corona española y — como consecuencia de ello - en la configuración de los países que surgen en América Latina. Sin embargo, luego de expresarlo, suelen dedicarse a narrar o analizar algún acontecimiento que ayude a explicar aspectos de ese proceso largo y complejo. Pero se deja de lado — generalmenteque en el proceso de configuración del Estado-nación peruano hay dos elementos que deben considerarse con la misma importancia. El primero sobre cómo se va construyendo la comunidad política que deberá integrar a las y los peruanos, y el segundo sobre cómo los otros, los no peruanos, el resto del mundo percibe esa nueva realidad e inicia un derrotero de inserción en el concierto de las naciones (Vázquez 2003a). Así, la nación, «una comunidad política imaginada como inherentemente limitada y soberana» (Anderson 1997, 23), requiere para ser tal que los «otros» países, las otras comunidades políticas, la incorporen como una más, y reconozcan sus límites y su capacidad de decisión sobre sus asuntos internos. A estas alturas, se comprenderá que el mayor énfasis historiográfico ha recaído en el primer componente de este binomio. Mientras que, sobre el segundo asunto, ha recibido menos interés de parte de los estudiosos del tema, aunque por supuesto con notables excepciones (Aljovín y Chávez 2012, Pereyra 2013, Aljovín y Velásquez 2014, Novak y Namihas 2020, Buller 2021, entre otros).

En ese sentido, el nacimiento de la república implicaba no solamente proclamar la independencia, definirla militarmente, diseñar las instituciones políticas, conformar la nación, sino también lograr el reconocimiento en el concierto internacional. Así, a pesar de que las nacientes repúblicas eran vulnerables, su mayor activo era la solidaridad existente entre todas (Buller 2021, 
503 y 511). Es del caso recordar que el Perú fue sede del virreinato del Perú y sus dimensiones — en un principio - ocuparon casi toda Sudamérica con excepción del Brasil, pero a partir de la segunda mitad del siglo XVIII sufrió dramáticas modificaciones, entre las más importantes estuvo la división del territorio en dos virreinatos adicionales y dos capitanías. Ello significó no solo la pérdida de territorio y de poder, sino que los nuevos espacios rivalizarán con el virreinato del Perú por el control del comercio y recursos (Pereyra 2013, 95). Junto a esos procesos se añaden el desplazamiento del poder eclesiástico por el poder militar y el debilitamiento del Pacífico a favor del Atlántico (Fisher 2000, capítulos 2 y 3). La dinámica de esos procesos trascendió la colonia y configuró a los nuevos países.

Asimismo, es necesario tener presente que en este territorio se definió la libertad de América del Sur, cuando el Ejército Unido Libertador ganó consecutivamente las batallas de Junín y Ayacucho en 1824. Ello significa que los otros países de la región consideraban que, sin la independencia del Perú, sus propias independencias no estaban aseguradas (Zuloaga 2021, 14; Sobrevilla 2021, 64; O'Phelan y Lomné 2013; Estenssoro 2021). En ese sentido, en la configuración de las nuevas repúblicas, el Perú debía tener un territorio y recursos que dieran lugar a un equilibrio de poderes entre todos los países, principio en boga en ese entonces a partir del Congreso de Viena de 1815 (De la Torre 2015). Finalmente, vale considerar que, durante los primeros años, la presencia de Riva Agüero en el exilio hizo que los ministros plenipotenciarios peruanos en Europa estén atentos a sus acciones, pues durante los casi diez años que estuvo fuera, desarrolló una intensa campaña contra la imagen de Bolívar que era reproducida especialmente en Londres (Hernández 2019).

A partir de lo expresado, a continuación se desarrollarán tres aspectos. El primero comprende una mirada panorámica de las características de la organización de las relaciones exteriores peruanas, la misma que ha sido organizada en cinco coyunturas críticas, incidiendo brevemente en la primera. Luego, como segundo aspecto, se dará cuenta de las características y principales hitos de las relaciones del Perú con algunos países de la región, con España y la Santa Sede. Estas se caracterizaron por la suscripción de tratados y convenios. En ninguno de los casos, con los países vecinos, los límites se definieron en este periodo. Se aprecia — además — que seguimos el mismo camino del conjunto de la región. Es decir, de relaciones fraternas a conflictos, muchos de los cuales dieron lugar a guerras. Finalmente, se repasará el Congreso de Panamá, como iniciativa de coordinación supranacional en el proceso de configuración 
de los Estado-nación latinoamericanos. Con ello interesa demostrar a la independencia como el inicio de un largo proceso de reconocimiento y de inserción del Perú en el concierto de las naciones, debido a la inestabilidad política de buena parte del siglo XIX, al Estado de baja capacidad que caracterizó al Perú de entonces y al contexto internacional adverso a partir del Congreso de Viena, expresión de un orden internacional posnapoleónico.

\section{Una mirada panorámica de las relaciones exteriores peruanas durante gran parte del siglo XIX}

El proceso de inserción del Perú al concierto de naciones fue largo, sinuoso y pasó por varios momentos. A diferencia de otros países de la región, en el territorio peruano convergieron los dos grandes ejércitos patriotas sudamericanos que buscaban garantizar la independencia de sus respectivos países. Sus líderes estaban convencidos de que no era posible sostener en el tiempo sus independencias si no expulsaban del continente al poder español ubicado en el virreinato del Perú. Asimismo, hubo períodos en que los peruanos de entonces consideraron que era bueno coordinar con los países vecinos para la defensa e intercambio internacional en mejores condiciones. Otras veces la guerra fue el camino para resolver temas problemáticos como el pago de la deuda, definir los límites de las fronteras o demostrar a España que ya no había marcha atrás.

Del proceso de la independencia hasta la guerra del Pacífico, el Perú protagonizó gran parte del siglo XIX caracterizado por pasar de un régimen con instituciones económicas y políticas extractivas a uno con instituciones políticas inclusivas, pero conservando las instituciones económicas extractivas. Ello dio lugar a un periodo de alta inestabilidad política (Acemoglu y Robinson 2012). Internamente el Estado era de baja capacidad (Tilly 2010) y externamente mantuvo los ideales y valores de instituciones políticas inclusivas. Sin embargo, tensión y conflicto fueron las expresiones de dicha inestabilidad. Paradójicamente, en el año de la guerra con Chile se produjo el reconocimiento de España al Perú, cerrando así un largo periodo de inserción en el concierto de naciones.

Ese derrotero complejo y sinuoso podría explicar las razones por las cuales el reconocimiento de la antigua madre patria demorara tanto. En efecto, a diferencia de otros países de Hispanoamérica que lograron el reconocimiento de España durante la primera mitad del siglo XIX, el nuestro demoró alrededor de cinco décadas. Por ello, en este acápite nos salimos de los límites 
cronológicos del proceso de la independencia que suele considerar un periodo de 1780 a 1830, y optamos por el que denominamos «siglo XIX corto», que se inicia con la proclamación de la independencia en Lima en 1821 y culmina con la salida del ejército chileno del territorio peruano en 1883. Este proceso no puede ser visto al margen del contexto global, de la actuación de las potencias europeas y los Estados Unidos, ni de los procesos similares de las nacientes repúblicas hispanoamericanas.

¿Qué sucedió en este periodo en el Ministerio de Relaciones Exteriores? De manera muy sintética podemos señalar que durante los sesenta y dos años que comprenden el siglo XIX corto (1821-1883), el Ministerio de Relaciones Exteriores peruano tuvo un total de ciento cuarenta encargados en esa cartera. Siendo el primero designado como secretario de Estado de Relaciones Exteriores Juan García del Río en 1821 y el último José Antonio de Lavalle en 1883. Es decir, el número de ministros es alto, dado que hubo alrededor de dos ministros de Relaciones Exteriores por año. Esta cifra puede expresar la inestabilidad política que se vivió durante este periodo (Demélas 2003), así como la baja capacidad del Estado (Tilly 2010). De ellos, se puede señalar que veintiséis estuvieron a cargo de la Cancillería entre dos a siete oportunidades, destacando José María de Pando (cinco veces), así como Manuel del Río y Matías de León hasta en siete oportunidades. Asimismo, haciendo un repaso panorámico de todo el período, podemos identificar cinco coyunturas críticas (Acemoglu y Robinson 2012). En términos cuantitativos, esto se expresó en el número alto de cambios ministeriales en Relaciones Exteriores. Es decir, en dichas coyunturas críticas hubo de diez a más ministros de Relaciones Exteriores en un tiempo relativamente corto. Hubo incluso más de tres ministros en un solo año, tal como se puede apreciar en la siguiente tabla:

TABLA 1

Periodos en los cuales hubo mayor número de ministros de Relaciones Exteriores en el Siglo XIX

\begin{tabular}{|c|c|c|c|}
\hline \multirow{2}{*}{ Ord. } & \multicolumn{2}{|c|}{ Coyuntura crítica } & \multirow{2}{*}{$\begin{array}{c}\text { Número de ministros de } \\
\text { RR. EE. }\end{array}$} \\
\cline { 2 - 3 } & Inicio & Fin & 10 \\
\hline 1 & $26-02-1825$ & 1827 & 16 \\
\hline 2 & $31-01-1832$ & 1835 & 14 \\
\hline 3 & $11-02-1843$ & 1845 & 13 \\
\hline 4 & $10-04-1864$ & 1867 & 20 \\
\hline 5 & $20-05-1879$ & 1883 & . \\
\hline
\end{tabular}

Fuente: Página Web del Ministerio de Relaciones Exteriores. Elaboración propia. 
No hay espacio para explicar estas cinco coyunturas críticas, y hacerlo nos distanciaría del tema a tratar. Solo analizaremos la primera que corresponde al periodo 1825-1827, cuando después del triunfo de Ayacucho, Bolívar va al Alto Perú e Hipólito Unanue asume la Presidencia del Consejo de Gobierno del Perú (Casalino 2020a). Luego se produce el retorno de Bolívar, pero al ser llamado a Colombia para resolver asuntos urgentes, le sigue la Junta de Gobierno presidida por Andrés de Santa Cruz y esta coyuntura se cierra cuando inicia el Gobierno de José de La Mar. En esos años, el ambiente - liderado por los criollos limeños - se vuelve nacionalista, se distancian de Bolívar y buscan la expulsión de los extranjeros que tenían responsabilidades públicas (Rojas 2017). El resultado político de todo el proceso de la independencia será que los hombres libres pueden participar en las elecciones para elegir a las autoridades. Ello significa que las instituciones políticas son inclusivas y se diferencian radicalmente de las instituciones políticas absolutistas del periodo colonial, donde la autoridad lo era por legitimidad dinástica, matrimonio o guerra, además de concentrar todo el poder y las decisiones (Casalino 2020 b).

En efecto, desde el periodo del protectorado de San Martín hubo roces entre los extranjeros y los limeños, pues tal como sostiene Rojas $(2017,48)$ :

los hombres que llegaron con el ejército libertador habían pasado por la experiencia exitosa de destruir el sistema colonial en sus «países». Habían comprobado el poder de cambiar un régimen político y se auto percibieron como agentes de la libertad americana. Al contrastarse con los limeños, quienes carecían de un ejército revolucionario como el acaudillado por San Martín o Bolívar, se concibieron superiores y construyeron una visión negativa del habitante de Lima.

A partir de esas percepciones de superioridad, una vez lograda la independencia, los extranjeros consideraban que, si los habitantes de Lima no habían luchado por su liberación, tampoco estaban preparados para autogobernarse. Ese fue el argumento para que San Martín pase de Libertador a Protector (Sobrevilla 2021, 105-106). Es decir, ejecutar su revolución sin guerra (Lynch 2009) implicaba que la definición debía ser política y no militar. Es cierto también que el Protector tenía una propuesta monárquica para el caso peruano como una transición política de una sociedad cuya cultura política era cortesana y absolutista (Rojas 2017, 53-57). Recuérdese también que la salida monárquica era tolerada por la Santa Alianza, tal como lo hicieron con el Imperio del Brasil y el Imperio mexicano, por lo que una salida monárquica 
podría haber allanado el camino del reconocimiento internacional (Zuloaga 2021, 230).

En el caso de Bolívar la situación fue similar. Los peruanos - especialmente los criollos limeños - lo necesitaban, pero a la vez lo detestaban. Algunos de sus detractores consideraban que la presencia de ambos libertadores debía restringirse a garantizar la independencia y luego dejar el gobierno a los peruanos; otros plantearon un discurso en el sentido que, si bien no habían organizado un ejército, habían desarrollado un «guerra de opiniones», conspirado e incluso convencido al batallón Numancia para que pase al ejército patriota. También había diferencias ideológicas, ya sea por ser conservadoras o por liberales. Así fue como surgieron diversas conspiraciones contra Bolívar, y a la vez hubo reacción de parte de los seguidores de Bolívar contra los peruanos, chilenos y argentinos principalmente. Bolívar, a su vez, debía marcharse a la Gran Colombia que tenía sus propios problemas de liderazgo entre Santander y Páez. En el Perú fue mutua la desconfianza entre los seguidores de Bolívar y los antibolivarianos. Incluso Necochea, Guise, entre los extranjeros, y Luna Pizarro, Mariátegui, Arce, sufrieron persecución, prisión y exilio, pues no aceptaban la presidencia vitalicia de Bolívar. Fue así como los peruanos se liberaron de Bolívar y se quedaron con el poder, pero comenzó la lucha fratricida dando lugar a la era del caudillaje y a la inestabilidad política. El 8 de marzo de 1826, las tropas grancolombianas abandonaron territorio peruano. Ya antes, se habían enfrentado las tropas nuevo-granadinas con las venezolanas, dando cuenta de lo difícil que estaban las cosas en la Gran Colombia (Lynch 2006, O'Phelan 2019, Pino 2021).

En esta primera coyuntura crítica hubo diez ministros de Relaciones Exteriores: Hipólito Unanue (en dos oportunidades), Tomás de Heres, José Morales, Manuel L. Ruiz de Pancorvo, José Serra, José María de Pando, Manuel R. Vidaurre, Manuel del Río y Francisco Javier Mariátegui. Hipólito Unanue ya había tenido esta cartera un año antes, luego a la muerte de José Faustino Sánchez Carrión tuvo que ocupar su lugar. Durante su segunda oportunidad a cargo del ministerio — cinco meses-, firmó el reglamento de elecciones municipales y emitió un decreto para resguardar el orden público al interior de la capital ante la falta de tropas de línea. En junio de 1825 retornó al Ministerio de Gobierno y Relaciones Exteriores, después de haber presidido el Consejo de Gobierno del Perú. En dicha oportunidad se establecieron penas para los introductores de libros obscenos, se dispuso que el departamento de Huánuco se denomine Junín, que se establezca una escuela normal en el 
Convento de Santo Tomás y la creación de escuelas primarias en las porterías de los conventos.

El venezolano Tomás de Heres tuvo varias responsabilidades de alto nivel en el Perú. Por ejemplo, fue nombrado jefe del Estado Mayor General del Ejército Libertador, prefecto del departamento de La Libertad en 1824, fue secretario general de los Negocios de la República peruana, ministro de Guerra y Marina. Cuando estuvo a cargo del Ministerio de Gobierno y Relaciones Exteriores en abril de 1825, se llevó a cabo la determinación de las jurisdicciones de las cortes superiores, acciones en defensa del orden en la capital, el establecimiento de la Dirección General de Estudios y la asignación de rentas para el Colegio del Príncipe. José Morales, limeño y prócer de la Independencia, asumió el Ministerio de Gobierno y Relaciones Exteriores en junio de 1825 . Pero ya tenía experiencia en este rubro, pues había sido ministro plenipotenciario ante la corte imperial de México en 1823. Cuando regresó al Perú, fue nombrado oficial mayor del Ministerio de Gobierno y Relaciones Exteriores y luego ministro de manera interina. Suscribió un decreto convocando al Congreso para que se instale en la capital en febrero de 1826. Manuel Ruiz de Pancorvo había sido vocal y presidente de la Corte Superior de Lima, así como oficial mayor del Ministerio de Gobierno y Relaciones Exteriores. Cuando desempeñaba esta última función, fue que le tocó reemplazar a Unanue cuando dejó el ministerio. Su principal labor respecto a relaciones exteriores fue coordinar con los representantes del Perú enviados a Panamá al Congreso Anfictiónico. En el caso del siguiente ministro de Gobierno y Relaciones Exteriores, José Serra, primero fue el oficial mayor de ese ministerio y de ahí pasó a hacerse cargo de la cartera. Durante su periodo al mando, se encargó del censo para fines electorales.

Luego de Serra, fue designado José María de Pando como titular del Ministerio de Gobierno y Relaciones Exteriores. Al igual que sus antecesores, tenía mucha experiencia en altas funciones, incluso durante el periodo colonial. Estaba en Panamá como ministro plenipotenciario cuando fue convocado para dirigir el ministerio. Durante su gestión se reconoció a Bolivia como estado soberano e independiente, sin embargo, el tratado de paz y amistad incluía serias desventajas para el Perú, pues bajo los principios de equilibrio de poderes, se estaba generando una nueva república a la que debía dársele salida al mar, la misma que significaba cesión del territorio peruano. Fue el último ministro de la era bolivariana. 
Bajo el mandato de la Junta de Gobierno presidida por Andrés de Santa Cruz, estuvieron en el Ministerio de Gobierno y Relaciones Exteriores Manuel Vidaurre y Manuel del Río. Fue a este último que le tocó la declaración de nulidad de la Constitución vitalicia y la determinación de las facultades del presidente de la república. Luego, durante el Gobierno de José de La Mar, se encargó dicha cartera a Francisco Javier Mariátegui, quien tuvo a su cargo el reconocimiento del derecho del Alto Perú para ser Estado soberano. Los tres últimos ministros se habían distanciado de Bolívar una vez que fue proclamado presidente vitalicio.

Vale la pena destacar que el primer encargado de las relaciones exteriores del Perú, Juan García del Río, expresó las características de la época, pues fue canciller de Chile, del Perú y de Colombia, así como ministro de hacienda del Ecuador (Buller 2021, 511). Asimismo, en esta primera coyuntura crítica, destacaron como ministros de relaciones exteriores Hipólito Unanue, José María de Pando, Manuel Vidaurre, Manuel del Río y Francisco Javier Mariátegui. En dichos nombramientos se expresa el proceso por el cual los seguidores de Bolívar son desplazados por criollos limeños antibolivarianos.

En síntesis, el proceso de independencia dio lugar a una coyuntura crítica que generó las condiciones para cambiar las instituciones políticas. Durante el proceso emancipador, las instituciones políticas extractivas fueron cambiadas por instituciones políticas inclusivas, sin embargo, las instituciones económicas se mantuvieron extractivas. Esa combinación de instituciones políticas inclusivas e instituciones económicas extractivas tuvo como consecuencia inestabilidad política que duró hasta fines del siglo XIX, generando a lo largo del mismo tensiones y conflictos, donde se aprecian periodos cortos de mayor intensidad de la violencia. Este periodo se cierra con la coyuntura crítica 1879-1895, que logra que se cambien las instituciones políticas por unas de carácter extractivo y excluyente. Fue así como en 1896 se logra cierta estabilización política y económica a costa de expulsar del sistema político a la gran mayoría de la población, la cual pugnará a lo largo del siglo XX por ser incluida en el sistema.

Esa inestabilidad política se expresará en el Gobierno. De ahí que en el sector de Relaciones Exteriores el país haya tenido ciento sesenta ministros, algunos de los cuales duraron pocos días en el poder. Incluso hubo quienes no tenían experiencia en ese campo. Por eso — salvo contadas excepciones-, no pudo formarse una burocracia especializada que hiciera carrera pública y que se mantuviera a pesar de los cambios gubernamentales. Probablemente por esa escasez de expertos, algunos de ellos tuvieron que repetir la responsabili- 
dad de ser titulares de ese ministerio tres o más veces. Por lo tanto, podemos encontrar casos como Manuel del Río y Matías de León, quienes fueron ministros de Relaciones Exteriores hasta en siete oportunidades. Les siguieron José María de Pando, quien fue cinco veces ministro. Hubo tres ministros que lo fueron hasta en cuatro oportunidades: José Antonio Barrenechea, José Fabio Melgar y José Gregorio Paz Soldán. Finalmente, Hipólito Unanue, Juan Antonio Ribeyro, Manuel Ferreyros y Toribio Pacheco lo fueron hasta tres veces. Varios de ellos, dejaron huella, a pesar de la inestabilidad mencionada y las pocas posibilidades que tuvieron de construir una trayectoria en este campo. De esos que destacaron a pesar de sus circunstancias, Raúl Porras Barrenechea sostuvo en 1956 que la política diplomática peruana se caracterizaba porque desde el principio de la república hubo una orientación internacional (Casalino 2021, 226), la cual se encontraba:

en defensa de las situaciones de derecho, sobre las situaciones de fuerza y en defensa de la coordinación de los esfuerzos internacionales desde la Circular del Congreso de Panamá enviada por Sánchez Carrión hasta los Congresos del 48 , convocados por Castilla, en pleno peligro del imperialismo español y luego nuestra política se continuó por nuestra Cancillería, protestando contra todos los atentados de fuerza de América, contra la ocupación de México, favoreciendo la libertad de Cuba y apoyando al Paraguay contra las fuerzas tripartitas de Argentina, Brasil y Uruguay. Creo que, precisamente, en el campo internacional y en medio de las vacilaciones anárquicas del caudillismo interno, hemos tenido un firme rumbo que ha orientado nuestra política internacional que ha prevalecido en todos nuestros conflictos y, por medio de la cual hemos obtenido grandes triunfos, como en la afirmación de nuestros derechos sobre la Amazonía (Porras 1956; en Casalino 1999, 49-50).

A continuación, se desarrollará el proceso del reconocimiento de la independencia y cómo se produjo la inserción del Perú en el concierto de naciones.

\section{El proceso de reconocimiento de la independencia y las relaciones exteriores}

En este acápite abordaremos dos aspectos centrales. En primer lugar, el proceso de reconocimiento de la independencia del Perú, lo que implicaba el estatus 
de un nuevo país en el concierto de las naciones. Es decir, nos concentraremos en las gestiones realizadas por el Ministerio de Relaciones Exteriores para lograr el reconocimiento como una nación libre y soberana. En segundo lugar, analizaremos las características de las relaciones exteriores que el Perú desarrolló.

Sobre este asunto, es necesario recordar como precedente la división durante el periodo borbónico en tres virreinatos - Perú, Nueva Granada (17171739), Buenos Aires (1776) — y dos capitanías (Chile y Venezuela). Desde ese momento se originan disputas por el comercio de los puertos, por los recursos - como por ejemplo el Alto Perú-, por la hegemonía en la región, el desarrollo de una política comercial y el comercio libre. Todo ello tuvo injerencia en las relaciones que las nacientes repúblicas llevarían a cabo una vez logradas sus independencias (Pereyra 2013, 95-98). Hemos dicho que el virrey Abascal encarnó el Estado absolutista español en nuestro territorio y, en ese sentido, cuando se produjo la crisis política española de 1808, entre sus primeras medidas estuvieron la anexión del Alto Perú a la autoridad de Lima ante la amenaza de la insurrección rioplatense (Pereyra 2013: 104, O'Phelan y Lomné 2013).

La primera misión enviada al exterior fue en enero de 1821, cuando Tomás Guido parte rumbo a Guayaquil por encargo de José de San Martín y se firma un tratado en el cual se establece que Guayaquil conservaba su autonomía y se declaraba bajo protección del Libertador San Martín. La segunda tuvo como destino Europa y estuvo a cargo de Juan García del Río, el primer ministro de Gobierno y Relaciones Exteriores, y James Paroissien, médico general del Ejército Libertador. El objetivo de la misión era ofrecer el trono del Perú a un príncipe europeo y gestionar un préstamo. Un año después de la proclamación de la independencia, y ante la situación estancada en que se hallaban los ejércitos patriotas y realistas en el Perú, San Martín se entrevista con Bolívar en Guayaquil, encargando el mando a Bernardo Monteagudo, quien era el ministro de Gobierno y Relaciones Exteriores, y años después - 1825- escribiría un ensayo «Sobre la necesidad de una Federación General entre los Estados Hispanoamericanos». Bolívar se encontraba en su etapa de gloria, pues había consolidado las independencias de Nueva Granada, Venezuela y Quito con sendos triunfos militares. Luego de esa entrevista, y ante la pérdida de legitimidad entre los criollos limeños, José de San Martín decidió dejar el Protectorado y entregar el poder al Congreso retirándose del país en septiembre de 1822. El Congreso dejó sin efecto la misión diplomática de García 
del Río en lo que correspondía al príncipe europeo y mantuvo lo referido al préstamo. Pero, un año después de la partida de San Martín, los peruanos no lograban continuar y menos ganar la guerra de independencia, solo habían avanzado en redactar su carta fundamental. De esa manera podemos apreciar que el Perú inició su recorrido como Estado-nación asumiendo los principios del derecho internacional público para insertarse en el concierto internacional y en el ámbito interno organizándose bajo los principios del constitucionalismo (Pereyra 2013, 110-111; Anna 2003; Dager 2006; Lynch 2006 y 2009).

A la partida de San Martín, el Congreso designó un triunvirato a cargo del Ejecutivo, pero luego se impuso la presidencia de José de la Riva Agüero, a través del motín de Balconcillo. Sin embargo, no se logró organizar un ejército - sobre la base del que había traído San Martín y nuevos contingentesque diseñe una estrategia militar y se sobreponga a los realistas. Así fue como el Congreso decidió invitar a Bolívar al Perú, para que con su ejército del norte lograra el triunfo militar de una independencia a punto de perderse. El Congreso nombra presidente a José Bernardo de Tagle y Portocarrero, marqués de Torre Tagle. Fue en este periodo que se aprueba el Tratado de Unión Liga y Confederación con Colombia; el ministro de ese entonces era Juan de Berindoaga Conde de San Donás. Una vez en el Perú, Bolívar gobernó con el ministro José Faustino Sánchez Carrión y reorganizó un ejército, al que sumó las fuerzas gran colombianas. Al inicio de 1824, Bolívar nombra ministro de Gobierno y Relaciones Exteriores a Hipólito Unanue; después en octubre de ese año designa ministro a José Faustino Sánchez Carrión, quien firma las comunicaciones de convocatoria para el Congreso de Panamá a realizarse en 1826. Si seguimos a Pereyra, debemos tomar en consideración que Bolívar en el Perú no dejó de pensar en el principio de equilibrio de poderes y, desde esa perspectiva, buscó equilibrar el poder de la región para que Colombia no sea menor y el Perú siguiera perdiendo la hegemonía política, tendencia que provenía desde las reformas borbónicas (Pino 2021; Pereyra 2013, 113).

Respecto al proceso de reconocimiento de la independencia, el derrotero peruano fue similar al del resto de los países de la región. Un punto importante fue el reconocimiento, por parte de los Estados Unidos, de los nuevos Estados hispanoamericanos en marzo de 1822, decisión que comunicó a todas las cancillerías en julio de dicho año. A inicios del año siguiente (15-01-1823), México reconoció al Perú como país independiente. En ese mismo año, se firmó un segundo tratado con la Gran Colombia para precisar el tipo de ayuda económica y militar de esta para la independencia peruana. Asimismo, se ini- 
ció nuestra historia de la deuda externa con el primer préstamo de 1200000 libras esterlinas, abriendo a su vez la triste historia de corrupción, abusos de funcionarios, negocios impropios e incompatibles con la misión de proveer fondos para el Estado a fin de enfrentar los gastos de la independencia. A inicios de 1824, llegó el primer cónsul de una potencia extranjera; se trataba de William Tudor, representante de los Estados Unidos. En 1825, Inglaterra reconoció la independencia de los países hispanoamericanos, dejando pendiente al Perú. Al año siguiente se establecieron relaciones diplomáticas con representantes formales entre el Perú y los Estados Unidos (Dager 2006, 347351; Quiroz 2013, 136-144; Pereyra 2013, 123).

Una vez logrado el reconocimiento, había que definir los límites con los países vecinos, establecer relaciones comerciales, y buscar recursos para atender la deuda externa, entre otras tareas propias de este sector. En el caso de la definición de los límites, había que seguir los principios del derecho internacional público, así como la tradición europea y la propia. Revisemos esto último a continuación.

Andrés Bello publicó en 1832 su obra titulada Principios de derecho de jentes, cuando se encontraba sirviendo al ministerio de Relaciones Exteriores de Chile y fue una referencia para los juristas de la región, quienes lo consideraron el padre de las relaciones internacionales de América Latina. Dicha publicación incluía un manual de diplomacia y un capítulo sobre el servicio consular. Abordó temas de sumo interés para la región como el derecho al reconocimiento de un Estado por los otros o las limitadas causas que justifican el derecho de intervención. En el caso del reconocimiento, Bello (2003 [1832], 87) sostenía lo siguiente:

Si se presenta pues un Estado nuevo por la colonización de un país recién descubierto, o por la desmembración de un Estado antiguo, a los demás Estados solo toca averiguar si la nueva asociación es independiente de hecho, y ha establecido una autoridad que dirija a sus miembros, los represente, y se haga en cierto modo responsable de su conducta al universo. Y si es así, no pueden justamente dejar de reconocerla, como un miembro de la sociedad de las naciones.

De esa manera, Bello considera que mientras se está llevando a cabo la contienda de separación de una antigua nación, los demás Estados pueden abrazar alguna de esas causas —a favor de la metrópolis o a favor de las provincias-. Asimismo, que una vez definida dicha contienda y el nuevo Estado 
está en posesión del poder, «no hay ningún principio que prohíba a los otros reconocerlos por tales, porque en esto no hacen más que reconocer un hecho y mantenerse neutrales en una controversia ajena» (Bello 2003 [1832], 87). Ello significa, para este autor, que este principio está por encima de lo que el Congreso de Viena y los demás congresos de ese entonces habían acordado como parte del orden internacional.

José María de Pando, autor de la obra Elementos del derecho internacional, culminada en 1840 y publicada en Madrid — póstumamente- en 1852, organizó dicha obra en cuatro partes. La primera es preliminar, donde presenta aspectos conceptuales, una mirada histórica y el estado del arte de la ciencia del derecho internacional. La segunda parte aborda aspectos del derecho internacional en tiempos de paz. La tercera analiza el estado de guerra. Y la cuarta aborda temas diplomáticos: agentes, tipos y funciones. Se trata de una obra que tiene bastante influencia de la obra de Bello y de Martens. Cuando aborda el asunto del reconocimiento, sostiene que este no es otra cosa que el pueblo obedece y legitima al gobernante:

La legitimidad de estos no deriva sino de la libre obediencia de los pueblos. Desde que este hecho se halla fuera de duda, sería obrar inconsecuentemente rehusando reconocer como legítimo al gobierno de la nación que se ha constituido independiente. Por el hecho de esta libre obediencia se ha convertido en lo que llaman un gobierno de derecho (Pando 1852, 69).

Más adelante sostiene que generalmente los Gobiernos que han pasado por esas insurrecciones suelen pedir que no se reconozca al pueblo insurrecto. Pero eso es completamente infundado, pues lo que sucede es que puede tratar con dicho pueblo porque esas relaciones benefician a ambas. De esa forma, el que quedó desposeído no puede evitarlo ya que tampoco pudo conservar a ese pueblo (Pando 1852, 70). Respecto al reconocimiento, señala que la soberanía de un Estado no necesita ser reconocida por otro Estado, pero es prudente hacerlo:

Un Estado adquiere la soberanía, o cuando es fundado, o cuando se separa legítimamente de la dependencia en que se hallaba. Para que esta soberanía sea válida, no necesita que sea reconocida o garantida por una potencia extranjera... Sin embargo, es prudente hacerla reconocer expresa o tácitamente [...]. 
[... una vez establecida la posesión del nuevo Estado u Estados, no hay ningún principio que a los demás prohíba reconocerlos por tales; porque en esto no hacen más que reconocer un hecho y mantenerse neutrales en una controversia ajena (Pando 1852, 72-73).

Pando, quizá uno de los pocos diplomáticos que combinaba conocimiento y experiencia sobre relaciones internacionales en ese entonces, coincide con Bello en que el reconocimiento a un nuevo Estado implica únicamente el reconocimiento de un hecho. Es decir que - por diversas razones - ha surgido en el concierto de las naciones un nuevo Estado libre y soberano, y todos los demás Estados pueden iniciar formalmente sus relaciones con este.

Años después, José Silva Santisteban publicó en 1858 su Curso de derecho internacional o de gentes. Si bien sigue los principios del derecho internacional público de sus antecesores, se puede apreciar en su obra una mayor reflexión y mejor perspectiva, pues el paso de los años contribuye a tener una expectativa menos apremiante sobre el reconocimiento de los Estados hacia los nuevos países. Ello lo lleva a distanciarse de las obras de sus predecesores:

El señor Bello, hombre experimentado e instruido, que escribía en una sociedad nueva, debió levantar su voz contra las prácticas inicuas y proclamar una reforma radical: pero no ha querido hacerlo, prefirió el papel de compilador al de reformador, el empirismo a la filosofía...

Más noble y elevado encontramos a nuestro compatriota D. José María Pando, cuya obra póstuma ha sido publicada en Madrid en 1843. Lerminier, Bello y otros autores se hallan textualmente copiados, pero en las reflexiones propias se vislumbran el talento de Pando y sus altas miras [...] (Silva 2018 [1858], 42).

Así es como Silva Santisteban identifica un punto de quiebre del antiguo derecho de gentes al nuevo derecho internacional a partir de la paz de Westfalia de 1648. Es en ese momento que se establece la igualdad social de las iglesias, tanto la de la reforma como la católica. Asimismo, se asume el «equilibrio político como principio regulador de las relaciones internacionales»; este último dio lugar a la intervención, y como correlato de ello, a las alianzas, pactos de familia, ligas y protectorados. Además, se instala formalmente el sistema de embajadas y las actividades de la diplomacia comienzan a especializarse hasta alcanzar su profesionalización (Silva Santisteban 2018 [1858], 30). 
Nuestro autor sostiene que toda nación tiene derecho a su personalidad, existencia y conservación. Este derecho es absoluto:

[...] luego que una asociación de pueblos comience a gobernarse por sí misma, luego que revele el hecho de su existencia propia, tendrá derecho de ser tratada y reconocida como nación sea cual fuere la amplitud de sus elementos constitutivos y el modo de verificarse su formación; una colonia que sacude el yugo de la metrópoli y se da una organización propia, debe ser reconocida como nación, sea que su desmembración hubiese sido violenta o pacífica; lo contrario sería rebelarse contra la evidencia de los hechos, estar viendo un hombre y tenerlo por fantasma (Silva 2018 [1858], 68).

Sobre la base de ese principio — derecho absoluto de las naciones a su personalidad-, Silva considera que no se puede ni debe esperar que la metrópolis española reconozca la independencia de sus antiguas colonias. De ahí que critica duramente a los que así pensaron y obraron. Recordemos que los peruanos en particular, y los hispanoamericanos en general, estaban ávidos por el reconocimiento de España, porque de esa manera pensaban que dejarían de ser vulnerables y por lo tanto corrían el riesgo de ser invadidos. Incluso el temor era a ser hostilizados o agredidos constantemente de diversas maneras. Así, nuestro internacionalista sostiene — siguiendo a Bello y a Pando- que la independencia es un hecho consumado. Si es o no reconocida por España, es lo de menos. El hecho del triunfo en las guerras de independencia y haber constituido gobierno no puede estar subordinado al reconocimiento español.

En síntesis, podríamos señalar que las naciones hispanoamericanas, entre ellas el Perú, se rigieron bajo el derecho internacional público de ese entonces para establecer sus relaciones con otros Estados. Asimismo, consideraron — siguiendo u oponiéndose - a la tradición europea, especialmente del sistema de congresos; y hubo principios americanos que tomaron en consideración, especialmente al momento de definir las fronteras. En ese sentido, en sus procesos de conformación del Estado-nación y sus relaciones con los demás, tomaron en consideración el reconocimiento entre Estados, el equilibrio de poderes, el principio de no intervención, la neutralidad, el utti possidetis jure sobre la base de 1809-1810, la libre determinación de los pueblos y la posesión efectiva. El Perú, al igual que los demás países hispanoamericanos, dieron énfasis de manera desigual a estos aspectos, criterios y principios (Pereyra 2013, Novak 2001). Si bien la historiografía coincide que fue a partir de 1846 
- que coincide con el final de la tercera coyuntura crítica señalada en líneas precedentes - que se sientan las bases de una política internacional, en el Perú en el sentido de dotar de mayores recursos y promover la profesionalización de sus funcionarios, siguió pendiente la búsqueda del reconocimiento de España (Novak y Namihas 2020).

A continuación, pasaremos a revisar las relaciones peruanas con otros países tanto de la región como europeos. Aquí es del caso hacer algunas precisiones metodológicas. Por limitaciones de espacio y porque se trata de una investigación más amplia que se encuentra en proceso, se ha privilegiado algunos episodios vinculados a los siguientes países: Colombia, Brasil, Ecuador, Bolivia, México, España y el Vaticano. Por lo tanto, se ha dejado de lado Chile, Argentina, Estados Unidos, Francia, Reinos Unido, entre otros que serán motivo de otro trabajo.

\subsection{Colombia}

Si seguimos a Porras en su Historia de los límites del Perú, podemos recordar que en las relaciones entre la Gran Colombia y el Perú hubo tres etapas. El primer periodo significó la firma del Tratado Monteagudo-Mosquera durante el protectorado de San Martín y fueron relaciones de intensa amistad y cordialidad. El segundo periodo fue el apogeo de la presencia de Simón Bolívar para lograr la independencia del Perú, lo que dio lugar a una relación casi confederada o de sometimiento a la Gran Colombia. La tercera etapa fue de violento desacuerdo, dando lugar a la guerra de 1828 a 1829, la que concluyó con la firma del Tratado de Guayaquil el 22 de setiembre de 1829 suscrito por José Larrea y Pedro Gual. Fue un «Tratado de paz, amistad, convenio de límites, navegación, comercio y otras relaciones internacionales» (Porras 1930, 49-54).

No obstante, esa apreciación de Porras requiere ciertos matices, pues desde un principio y para evitar conflictos inmediatos se dejó de lado el asunto de la definición de las fronteras, así como el asunto de Quito y Guayaquil. En el caso de Quito, desde la conquista y hasta las reformas borbónicas había pertenecido al virreinato del Perú, pero con las reformas borbónicas - ya mencionadas - pasó a ser parte del virreinato de Nueva Granada. Respecto a Guayaquil, se declaró independiente de España en 1820, y parte de su elite buscaba ser autónoma, pero otra parte pensaba anexarse al Perú. En este caso en particular, si bien durante las reformas borbónicas pasó a conformar 
Nueva Granada, en 1803 había retornado al Perú para garantizar su defensa, siendo revocada esta medida en 1819. Así, en el proceso de la independencia de Quito, confluyeron los ejércitos de Bolívar y San Martín, siendo el primero el que tuvo el liderazgo al llegar primero al territorio. Cuando Bolívar fue a Guayaquil, no solo se llevó a cabo la conferencia con San Martín, sino que consiguió - producto de fuertes presiones- que Guayaquil acepte su anexión a Colombia, a pesar de que Tomás Guido había firmado un tratado por el cual Guayaquil siendo autónoma pasaba a tener a San Martín como Protector. Incluso en el Tratado Monteagudo-Mosquera, considerado por Porras como un acto de intensa amistad, se puede tomar en cuenta que - siguiendo a Pereyra - durante las negociaciones para la firma de ese tratado, Monteagudo se negó a aceptar la anexión de Guayaquil a la Gran Colombia, pues el tratado con Guido había reconocido la independencia de Guayaquil. Posteriormente, en diciembre de 1823, el Perú y la Gran Colombia firmaron un tratado sobre sus fronteras: la Convención Galdeano-Mosquera, en la cual el Perú consideró que preservando Tumbes y la aplicación del uti possidetis de 1809 mantenía sus derechos sobre la selva. Sin embargo, la Gran Colombia, que conocía del título de 1802 y pensaba que era desconocido para los peruanos, asumió que el Perú había aceptado tácitamente su soberanía sobre la región amazónica. Esto era particularmente importante para los colombianos, pues Bolívar asumió que esa región era la «espalda» de la Gran Colombia desde su perspectiva de equilibrio de poder y posicionamiento de la Gran Colombia en el concierto internacional (Pereyra 2013, 114). Luego, en medio de la tensión entre el Congreso y el presidente José de la Riva Agüero, entre marzo y julio de ese mismo año, ambos enviaron delegaciones diplomáticas a la Gran Colombia y al mismo Simón Bolívar para que colaboren con fondos, soldados y, por supuesto, la estrategia militar del Libertador (Hernández 2019, 93-111; Bushnell 2010, 97-98).

La guerra entre el Perú y la Gran Colombia fue el acontecimiento más delicado que se vivió en los inicios de la vida republicana. Cuando se descompuso la Gran Colombia en 1830, los problemas fueron heredados por Ecuador y por Colombia. Tal como sostiene Pereyra, el aspecto central de la disputa estuvo en torno a las pretensiones gran colombianas sobre la hoya amazónica. Al inicio de 1828, el Gobierno peruano envió a José Villa para tratar de manejar la situación cada vez más conflictiva con Bogotá. El peruano no fue recibido por Bolívar, pero a través del ministro de Relaciones Exteriores se trató de que el Perú explique la salida del ejército gran colombiano del territorio 
peruano, la incursión/invasión del territorio boliviano para que sea expulsado Sucre y su ejército, la expulsión del ministro Armero, el pago de la deuda y la restitución de Jaén y la parte de Maynas. Dado que el gobierno gran colombiano no obtuvo respuesta de parte de Villa, se le devolvieron sus credenciales para que abandone el país. Así fue como Bolívar declaró la guerra al Perú en julio de 1828 (Pereyra 2013, 147).

Los peruanos llevaron a cabo una exitosa expedición naval en enero de 1829 y ocuparon Guayaquil. Los peruanos son detenidos en Portete de Tarqui. De manera simultánea, Gamarra promueve un golpe de Estado y La Mar es desterrado. El asunto en Guayaquil quedó en su devolución a la Gran Colombia, firmándose el Tratado Larrea-Gual donde ambas partes acuerdan que los límites serán los mismos que se tenían antes de la independencia. Así fue como las bases para el establecimiento de los límites serían los antiguos virreinatos de Nueva Granada y el Perú, con la posibilidad de hacerse pequeñas cesiones de territorio que contribuyan a fijar la línea divisoria de manera natural y exacta. Las comisiones demarcadoras que se determinaron a partir de ese tratado no pudieron reunirse. Luego se produjo la disolución de la Gran Colombia, por lo que recién en 1832 Ecuador firmó un arreglo de límites (Porras 1930, 49-54). Lo que vale la pena destacar en el caso de las relaciones entre Colombia y el Perú es que el tratado suscrito entre ambos fue el primero con un país extranjero (Bushnell 2010, 99).

Las siguientes décadas del siglo XIX corto no estuvieron exentas de potenciales conflictos, pero no llegaron a situaciones de guerra. Básicamente hubo tensiones porque el Perú aceptó la presencia de un líder opositor al Gobierno colombiano - Obando- quien escapó de su país debido a una insurrección fallida. En otra oportunidad el problema fue con Ecuador, y Colombia aliado de aquel estaba autorizado para declarar la guerra a quien apoye al líder insurrecto, Juan José Flores. Para evitar ello, el Gobierno peruano envió ministros plenipotenciarios, quienes se comprometieron al pago de la deuda que se tenía desde el inicio de la república (Aljovín y Velásquez 2014, 135).

\subsection{Brasil}

En el caso del Brasil, adicional al mutuo reconocimiento, era importante definir la frontera y regular la navegación por el Amazonas. En ese sentido, el Perú tuvo la iniciativa en 1826 de suscribir un tratado de límites, pero que no tuvo acogida por parte del imperio. Fue en ese año que el Gobierno designó 
—a propuesta de su ministro de Relaciones Exteriores José María de Pandocomo primer agente diplomático peruano en Brasil a José Domingo Cáceres, para que cumpliese las funciones de cónsul general en Río de Janeiro. En ese entonces, y a diferencia de lo que pensaban los ministros de Relaciones Exteriores de otros países hispanoamericanos de recelar del Brasil por haber optado por ser imperio y no república, el nuestro consideraba una buena estrategia el mutuo reconocimiento con dicho país vecino por las siguientes tres razones:

[...] primero como una forma de defenderse de posibles acciones de la Santa Alianza, con la cual Pedro I mantenía estrecho vínculo; segundo, como una forma de acercarse a Inglaterra y obtener su apoyo a la independencia, dada también la vinculación del imperio británico con el brasileño; y tercero, por el prestigio que implicaría para el Perú el reconocimiento y establecimiento de relaciones con un país importante como Brasil (Novak y Namihas 2012, 23).

Luego, en 1841 se firma un Tratado de Paz, Amistad, Navegación y Comercio en Lima entre Duarte da Ponte Ribeiro y Manuel Ferreyros, pero que no se llevó a cabo. Aljovín y Velásquez explican que ese tratado señalaba como base para una futura demarcación de fronteras entre ambos el principio de $u t i$ possidetis, pero el año base de referencia no era 1809-1810 sino 1821. Esto beneficiaba al Brasil, al reconocer de manera tácita el principio de posesión efectiva, pues Brasil había colonizado territorios al oeste de la demarcación de San Ildefonso. Adicional a ello, se firmó una convención que permitía el tránsito y comercio entre ambos países por el río Amazonas. Pero este tratado no fue ratificado (Aljovín y Velásquez 2014 126).

Sin embargo, Porras nos indica que dicha experiencia sirvió de base para la firma de la convención fluvial de 1851. Esta convención fue suscrita por Bartolomé Herrera y Duarte da Ponte Ribeiro, y expresaba el interés peruano por la libre navegación en el río Amazonas. Sin embargo, dicha convención fue muy discutida en la historia diplomática peruana porque incluía una cuestión de límites en un convenio fluvial, pues se admitió un uti possidetis sin fecha, favorable al Brasil, y porque no se hizo una delimitación completa, lo que dio lugar a conflictos no resueltos entre Brasil, Perú y Bolivia. En 1858 dicho acuerdo fue ratificado, por lo que otros países no podían navegar el Amazonas. En 1866 esa restricción fue modificada unilateralmente por Brasil (Porras 1930, 81-82; Aljovín y Velásquez 2014, 130). Visto en perspectiva, el 
Perú no tuvo manera de peruanizar el territorio amazónico en el siglo XIX, mientras Brasil desarrollaba una importante política de colonización sobre dichos territorios.

\subsection{Ecuador}

Una vez que la Gran Colombia quedó disuelta en 1830, fue necesario que el Perú reconozca a la República del Ecuador y actualice el tratado firmado el año anterior. Fue así como firmamos dos tratados, uno de alianza y amistad y otro de comercio, ambos ratificados por los respectivos Gobiernos. Durante ese tiempo no había cuestionamientos por parte de Ecuador sobre los territorios norteños y amazónicos peruanos. El problema surgió a partir de 1842, cuando uno de los caudillos fuertes del país del norte — Juan José Flores- buscó la expansión territorial del Ecuador a costa del territorio peruano, especialmente sobre La Libertad. El asunto se volvió más grave en 1841, pues Ecuador aspiraba anexar Jaén y Maynas, aprovechando que el Perú se encontraba en uno de sus momentos más inestables en términos políticos, pues salía de su fallida experiencia confederativa con Bolivia. Matías León fue el diplomático peruano encargado de tratar este asunto directamente. Este finalmente se resolvió porque el propio Ecuador tuvo problemas internos tan o más graves que los peruanos. Con el Gobierno de Echenique volvieron las dificultades, pues Juan José Flores estaba organizando una nueva insurrección y se apoyó en el Gobierno peruano. Finalmente, dada la presión internacional, especialmente de Colombia, el caudillo Flores fue proscrito del Perú. A inicio de la década de 1850 las tensiones se reavivaron, como consecuencia del acuerdo Perú-Brasil sobre libre navegación del Amazonas para ambos países. En ese sentido, los ecuatorianos discutieron en su Congreso un proyecto que otorgaba libre navegación de sus ríos afluentes al Amazonas (Chichipe, Santiago, Morona, Pastaza, Napo, Putumayo, entre otros). Si bien el Perú presentó una protesta por ese hecho, el proyecto fue promulgado. Este problema se fue agudizando hasta que llegó en 1858 a un punto crítico, cuando el Ejecutivo peruano fue autorizado por su Congreso para incrementar su ejército y su potencia bélica. Así fue como el Perú bloqueó la costa ecuatoriana. El Gobierno ecuatoriano entró en crisis y se fragmentó, incluso se firmó con una parte del Gobierno ecuatoriano el Tratado de Mapasingue, pero que luego fue desconocido por ambas partes (Aljovín y Velásquez 2014, 135-142). 


\subsection{Bolivia}

Las relaciones con Bolivia comienzan una vez que se le reconoce como república en 1825, de manera tácita, cuando Bolívar acepta que el Alto Perú sea independiente de Buenos Aires y del Perú, y se refuerza cuando en 1826 se firma el tratado de federación y límites. Si seguimos a Pereyra (2013), hay dos aspectos a tomar en consideración. El primero tenía que ver con el uti possidetis, pues si se aplicaba ese principio, el Alto Perú debería pasar a las Provincias Unidas del Río de la Plata y no al Perú. El segundo aspecto era que, si pasaba el Alto Perú al Perú, entonces se estaría generando un Estado fuerte y con recursos importantes como era la plata en ese entonces. De ahí que finalmente aceptara que el Alto Perú se independizara no solo de España, sino de Buenos Aires y del Perú. Pero para que sea un Estado viable y equilibrado, debía tener acceso al mar (Pereyra 2013, 125). Luego, Bolívar trató de mantener la unión política con el Perú y por ello envió a Ignacio Ortiz de Zevallos como ministro a Chuquisaca, quien firmó dos tratados, uno de federación (Federación Boliviana) y otro de límites (que fija la frontera peruano-boliviana en el río Sama, pasando así los departamentos de Tarapacá y Tacna a Bolivia). Ello significó la desaprobación por parte de Santa Cruz, a cargo del Gobierno en ese momento.

Cuando Sucre estuvo a cargo de la presidencia de Bolivia, le interesó resolver y definir una salida al mar para Bolivia. Asimismo, receló del Perú, especialmente cuando Bolívar y el ejército gran colombiano dejó el territorio peruano, pues Sucre quedó aislado. Pero, desde el punto de vista de los peruanos, consideraban que Sucre y su ejército en el sur podrían ser una amenaza si las relaciones con la Gran Colombia se deterioraban, pues un ataque en dos frentes no podría enfrentar. Fue así como en abril de 1828 se produjo el motín de Chuquisaca y Gamarra entró con su ejército ante el llamado de algunos bolivianos. La consecuencia de ello fue la salida de Sucre y del ejército grancolombiano de Bolivia. Luego de ello, el ejército peruano retornó al país (Pereyra 2013, 145-146). Con la salida de Bolívar, surge el enfrentamiento entre Gamarra y Santa Cruz, lo que se resuelve con la firma del Tratado de Arequipa el 8 de noviembre de 1831.

No hay conflictos de límites durante el periodo de la Confederación PerúBoliviana (1836-1839). Así, en 1839 se firma en el Cusco una convención preliminar de paz, y la demarcación de límites se haría tomando como punto de partida el Desaguadero. Años después - 1847-, se llega a un acuerdo (Tratado Elías-Aguirre) por medio del cual la frontera se señalaría por una 
comisión adoptándose por linderos los ríos, lagos o montañas (límites arcifinios). Al año siguiente, se estipuló que los límites serían los antiguos amojonamientos (Tratado Coronel Zegarra-Olañeta). El 5 de noviembre de 1863 se llegó al Tratado de Paz Ribeyro-Benavente. Una comisión estudiaría la carta topográfica de la frontera y los límites serán los que tenían ambas repúblicas. Pero en el año 1867 se produjo la delimitación limítrofe entre el Brasil y Bolivia, y en ese proceso afectaron territorio peruano, por lo que hubo protesta por el Tratado Muños-Neto de don José Antonio Barrenechea, ministro de Relaciones Exteriores en ese tiempo (Novak y Namihas 2013).

\subsection{México}

A inicios de octubre de 1821, Juan García del Río, ministro de Estado de Perú en la Secretaría de Relaciones Exteriores, envió una comunicación a la Suprema Junta del Gobierno del Imperio mexicano señalando los deseos de cimentar una unión entre ambos Estados. Meses después se recibió la respuesta mexicana suscrita por José Manuel Herrera. Ello podría llevar a la consideración de estar ante un reconocimiento tácito. El Perú nombró en 1822 a José Morales y Ugalde como ministro plenipotenciario ante el Imperio mexicano y a su vez este reconoció formalmente la independencia peruana.

Al año siguiente - 1823 - comenzaron a darse las primeras desconfianzas sobre el proceder de la otra parte. Todo empezó cuando el Congreso mexicano autorizó al Ejecutivo a celebrar tratados de comercio con representantes de la Corona española que residían en la ciudad de Jalapa. El plenipotenciario peruano expresó al ministro mexicano de Relaciones Exteriores sus temores sobre las consecuencias de dicha autorización sin que se haya producido el reconocimiento formal de la independencia, lo que pondría en riesgo aquellos territorios donde aún había ejércitos realistas, como era el caso peruano. La respuesta de Lucas Alamán fue contundente, en el sentido que no harían ninguna acción que ponga en riesgo a otras repúblicas americanas. Sin embargo, quedó evidente la posibilidad de que un país de la región llevara a cabo acciones unilaterales. Años después, ya en 1827, llegaron a México noticias alarmantes sobre los proyectos multinacionales de Bolívar a raíz del informe del ministro de Relaciones Exteriores peruano, Francisco Javier Mariátegui. En dicho documento daba cuenta de la presidencia vitalicia, de la Constitución bolivariana, de la federación desde Panamá hasta Cabo de Hornos, de las acciones de Bolívar contra el Perú ante una posible guerra con 
la Gran Colombia. Con toda esa información, Mariátegui solicitaba a México que mediara para defender la independencia del Perú, amenazada por las pretensiones de Bolívar y ante una guerra inminente de Bolivia y Colombia en contra del Perú (Palacios 2011, 47-48).

\subsection{España}

En el caso del reconocimiento de España, fue uno de los últimos actos formales en darse (1879). Ello a pesar de que desde las primeras conversaciones (1820) entre los representantes de San Martín y del virrey Pezuela se intentó llegar a acuerdos. Aljovín y Chávez (2012) sostienen que probablemente ello se debió a que la capitulación firmada en 1824 en el campo de batalla de Ayacucho dio lugar a puntos de conflicto que hicieron que, si bien se buscara allanar el camino del reconocimiento, ello no pudo darse. Por ejemplo, el asunto de la deuda que España pretendía que asumiera el Perú.

Luego, durante el Gobierno de Gamarra, se dieron las condiciones - Ley de 2-10-1839 - para iniciar relaciones comerciales, pero no se logró el reconocimiento (Aljovín y Chávez 2012, 288-289). Después, durante el ministerio de José Gregorio Paz Soldán —1854 - se intentó firmar un tratado, pero que no fue aprobado por Echenique ni ratificado por el Congreso de entonces. Cinco años después se volvió a intentar establecer relaciones con España, esta vez a cargo de Pedro Gálvez. En sus instrucciones estaban el separar el reconocimiento y dejar para otro documento diplomático el asunto de la deuda, pero no logró su objetivo y tuvo que regresar. Un tercer intento, que dio lugar a que se considere un reconocimiento implícito, fue en el contexto del conflicto con España originado por los incidentes en la hacienda Talambo y la captura de las islas de Chincha por la escuadra española. Ello dio lugar a la firma del Tratado VivancoPareja y como consecuencia de ello se envió en misión a España a Domingo Valle Riestra, quien, al ser recibido, dio lugar al reconocimiento implícito ya mencionado. Pero el desenlace de ello fue luego la declaratoria de nulidad por el siguiente Gobierno de Mariano Ignacio Prado (Chang 2013). Finalmente, recién el 14 de agosto de 1879 se llegó a suscribir un Tratado de Paz y Amistad.

\subsection{El Vaticano}

Respecto a las relaciones con la Santa Sede, los libertadores José de San Martín y Simón Bolívar retuvieron para sí el Patronato Regio. Especialmente 
Bolívar era consciente del papel central que tenía la Iglesia para educar a la población, de ahí que se aseguró el control de dicha institución que en ese contexto estaba en una situación inestable y crítica. Seis eran los obispados peruanos (Lima, Trujillo, Huamanga, Maynas, Cusco y Arequipa), pero solo había dos ocupados en ese tiempo (Cusco y Arequipa), pues tres habían sido exiliados (Lima, Trujillo y Huamanga) y uno se había retirado (Maynas). De ahí que una salida fue que los obispos dejaran un gobernador eclesiástico o deán en su reemplazo hasta que lleguen los nombramientos correspondientes (Hernández 2018, 226-227).

Cuando el papa León XII envió en misión hacia América al arzobispo Giovanni Muzzi entre 1823 y 1824, Bolívar estableció comunicaciones. Sin embargo, no era sencillo establecer relaciones, pues los primeros Gobiernos habían expulsado a varios religiosos por optar una postura realista y en contra de la independencia:

Apenas tuvo noticia Bolívar de la llegada de Mons. Muzzi, hizo que el ministro de Gobierno, José Sánchez Carrión, le dirigiese una carta (13/07/1824) en la que le manifestaba los «ardientes deseos» de entrar en relaciones con Roma, «por demandarlo urgentemente la salud espiritual de estos pueblos, el estado de orfandad a que se hallan reducidas sus Iglesias y el espíritu de fidelidad a la doctrina ortodoxa, depositada en la religión santa que profesa la república». Pero Bolívar fue más allá, pidiéndole en esta carta un Concordato entre la Santa Sede y el Gobierno del Perú (Hernández 2018, 244-245).

Si bien Muzzi respondió dicha comunicación, Hernández $(2018,245)$ refiere que no se logró conseguir todos los pedidos. Por ejemplo, Pedemonte obtuvo la facultad de administrar el sacramento de la confirmación, se aprobó la reducción de los días festivos. Si bien desde 1821 los libertadores habían solicitado contribuciones económicas a la Iglesia, examinaron el comportamiento de los eclesiásticos durante el proceso. Una vez ganada la batalla de Ayacucho, establecieron que las diócesis recién incorporadas jurasen la independencia. A partir de 1825, hubo reformas que implicaron intervención política en el ámbito eclesiástico. Por ejemplo, el 15 de noviembre de 1825 se decretó la intervención de la autoridad civil para la recaudación de los derechos parroquiales de los indígenas. Asimismo, se intervino en las demarcaciones territoriales de algunas diócesis. Luego se adoptó un nuevo arancel, que significaba la reducción en un tercio de los derechos parroquiales. Incluso 
Bolívar nombró a los obispos cuyas sedes estaban «vacantes»: a Pedemonte en Lima, a Echagüe en Trujillo, a Parral en Maynas y a Fernández de Córdoba en Huamanga (Hernández 2018, 233-240). Fue con Bartolomé Herrera que se retomaron las coordinaciones con la Santa Sede en 1852. Pero tampoco se pudo arribar a la firma de un concordato.

A manera de síntesis, podemos observar en la siguiente tabla la trayectoria del reconocimiento del Perú al establecer relaciones internacionales con otros países:

TABLA 2.

Trayectoria del reconocimiento

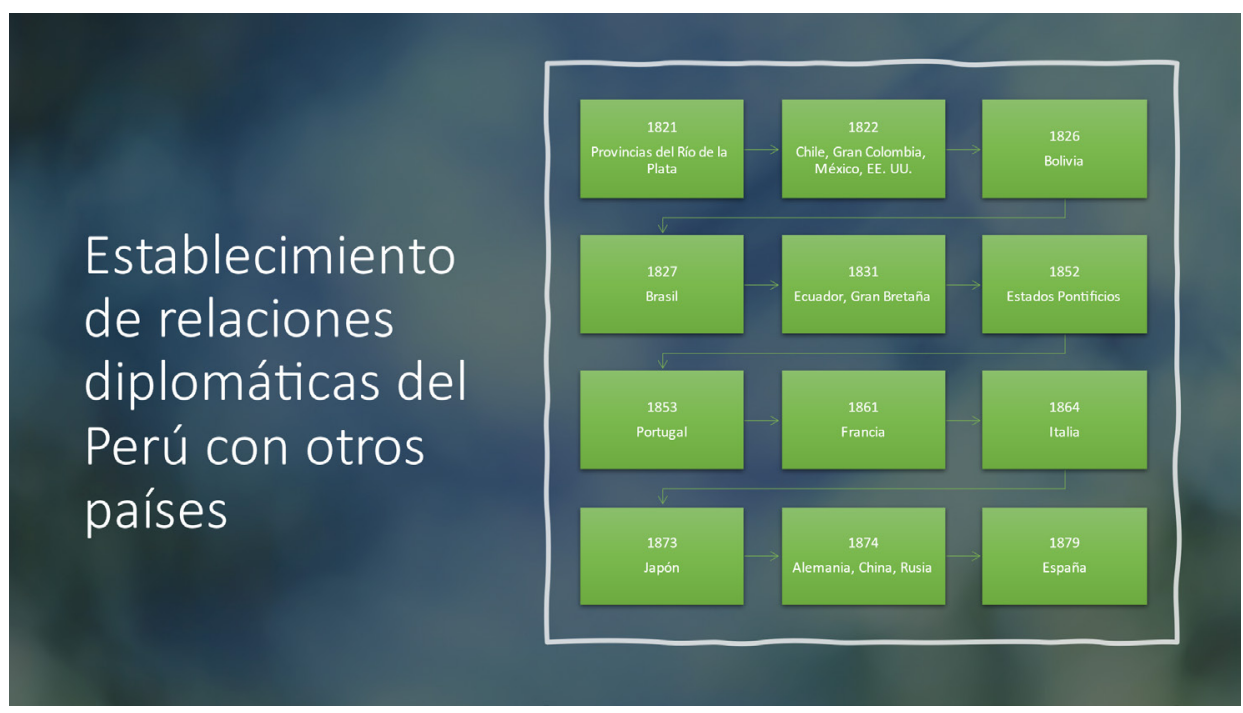

Fuente: Novak y Namihas (2020)

\section{El Congreso de Panamá, primera experiencia de coordinación supranacional}

Uno de los momentos cumbre de este periodo, por la visión estratégica que demuestra, será el intento por reunir a los nacientes países en un organismo coordinador de su seguridad y sus intereses. Según Porras Barrenechea (1926), se trata de un periodo en el cual las fuentes - correspondencia, documentos oficiales, entre otros - dan cuenta de la sinceridad y buena fe de la conducta peruana hacia los demás pueblos de América y del mundo. El concepto detrás del 
Congreso Panamericano llevado a cabo en Panamá fue promover una idea de solidaridad defensiva frente a la reacción de España que se negaba a reconocer a los nuevos países, así como el apoyo que esta recibía de la Santa Alianza, lo que podría dar lugar a una inminente invasión militar (Zuloaga 2021).

Sin embargo, la idea de coordinaciones entre los países, a través de un organismo supranacional, fue un largo proceso de toma de conciencia en el que participaron diversos pensadores, políticos y publicistas de Hispanoamérica. Porras reconoce en Francisco de Miranda - fundador de la Logia Americanay en Pablo de Olavide - fundador de la «Junta de las ciudades y provincias de la América Meridional»-como precursores de esta propuesta. Otros que también formularon propuestas similares fueron Cecilio del Valle (Centroamérica en 1810), Juan Martínez de Rozas (Chile en 1810), O’Higgins (Chile en 1818), Juan Egaña y el Satélite del Peruano (Perú) (Porras 1926, II-V). También encontramos figuras como Bernardo Monteagudo, quien apoya la propuesta de Bolívar (1825), o Lucas Alamán desde México, personajes que se dan cuenta que sin coordinaciones fraternas entre los países que están surgiendo serán presa fácil de los intereses y ambiciones de las grandes potencias, las que a su vez también actúan de manera coordinada. No solo eso, sino que las relaciones diplomáticas desde fechas tan tempranas y las firmas de tratados entre países de América Latina dieron lugar a una plataforma política previa que podía conducir a coordinaciones supranacionales tal como se proponía (O'Phelan 2019, 122).

$\mathrm{Al}$ respecto, es del caso señalar que, en primer lugar, hubo una concepción de la conformación de una confederación y para ello se instruyeron - en octubre de 1821 - a los ministros plenipotenciarios de la Gran Colombia, Joaquín Mosquera y Miguel Santamaría, para que aborden este tema cuando cumplan sus misiones en Perú, Chile, Buenos Aires y México. En segundo lugar, está la comunicación que Bolívar dirigió a los líderes de dichos Gobiernos en enero de 1822. En tercer lugar, están los tratados de unión, liga y confederación perpetua que debían firmar esos Gobiernos con la Gran Colombia.

Por ejemplo, entre los temas que debían abordar los comisionados, un aspecto central era la importancia de conformar una confederación entre estos Estados. Veamos lo que expresaba Bolívar al respecto:

[...] nada interesa tanto en estos momentos como la formación de una liga verdaderamente americana. Pero esta Confederación no debe formarse simplemente sobre los principios de una alianza ordinaria para la ofensa y defensa: debe ser 
mucho más estrecha que la que se ha formado últimamente en la Europa contra las libertades de los pueblos. Es necesario que la nuestra sea una Sociedad de Naciones hermanas; separadas por ahora y en el ejercicio de su soberanía, por el curso de los acontecimientos humanos, pero unidas, fuertes y poderosas para sostenerse contra las agresiones del poder extranjero. Es indispensable que V. S. encarezca incesantemente la necesidad que hay que poner desde ahora los cimientos de un cuerpo anfictiónico o Asamblea de Plenipotenciarios, que dé impulso a los intereses comunes de los Estados americanos y dirima las discordias que puedan suscitarse en lo venidero entre pueblos que tienen unas mismas costumbres y unas mismas habitudes, y que por falta de una institución tan santa, pueden quizás encender las guerras funestas que han desolado otras regiones menos afortunadas [...] (en De la Reza 2010, 8-9; los énfasis son nuestros).

En efecto, el propio Bolívar envió en enero de 1822, desde su cuartel general en Cali, comunicaciones a cuatro Estados que consideraba debían coordinar acciones para mantener y defender la libertad de América. Así fue como escribió a los gobernantes de Perú, Chile, Buenos Aires y México:

De cuantas épocas señala la historia de las naciones americanas, ninguna es tan gloriosa como la presente, en que desprendidos los imperios del Nuevo Mundo de las cadenas que desde el otro hemisferio les había echado la cruel España, han recobrado su libertad, dándose una existencia nacional. Pero el gran día de la América no ha llegado. Hemos expulsado a nuestros opresores, roto las tablas de sus leyes tiránicas y fundado instituciones legítimas; más todavía nos falta poner el fundamento del pacto social, que debe formar de este mundo una nación de Repúblicas [...].

La asociación de los cinco grandes Estados de América es tan sublime en sí misma, que no dudo vendrá a ser motivo de asombro para la Europa. La imaginación no puede concebir sin pasmo la magnitud de un coloso, que semejante al Júpiter de Homero, hará temblar la tierra de una ojeada [...] (en De la Reza 2010: 4; el énfasis es nuestro).

La tercera etapa en el proceso de construir dicha federación de naciones americanas era la firma de tratados de unión, liga y confederación perpetua, así como tratados para formar la asamblea de plenipotenciarios. Como ya se mencionó en acápites precedentes, el 6 de julio de 1822 se firmaron ambos tratados en el Perú entre el senador colombiano Joaquín Mosquera y el 
entonces ministro de Gobierno y Relaciones Exteriores del Perú, Bernardo Monteagudo. En el primero de esos documentos, ambos Estados se comprometen en apoyarse mutuamente cuando fuera necesario defender la independencia obtenida, asegurarse mutua prosperidad y armonía, intervenir cuando una de ellas esté en riesgo, facilitar la circulación de los ciudadanos de un país en el otro, facilitar el intercambio comercial y dejar para otro documento el asunto de los límites. El segundo documento se concentró en precisar la importancia, el objetivo y el mecanismo por el cual se llevaría a cabo una asamblea compuesta por plenipotenciarios representantes de ambas repúblicas (Buller 2021, 513).

Por lo tanto, la propuesta que formulaba Bolívar era que los cinco nuevos Estados hispanoamericanos debían conformar un nuevo pacto social, supranacional, que no solo de cuenta al mundo de su situación de Estados soberanos, sino sobre todo de su fortaleza. De esa manera seguían el ejemplo del Congreso de Viena, donde las potencias europeas se unían para organizar Europa después de Napoleón, y lo hacían sobre la base de nuevos principios, como hemos señalado antes. Es decir, siguen la pauta organizacional supranacional europea, pero esta es resignificada bajo otros principios y objetivos.

Los países hispanoamericanos buscaron en estas propuestas confederadas establecer medidas de protección para enfrentarse en mejores condiciones frente a los Estados Unidos y las potencias europeas. A mediados del siglo XIX surgieron nuevos ímpetus imperialistas en Europa, y los Estados Unidos comenzaron a materializar su «destino manifiesto» extendiendo su territorio a costa del territorio mexicano. Estas nuevas potencias sustentaban sus agresiones - bloqueo, invasión, reconquista, conquista, entre otras - por un sentimiento de superioridad - darwinismo-, para garantizar recuperar lo invertido y los préstamos realizados a las nacientes repúblicas, así como lograr condiciones ventajosas para el comercio.

En síntesis, tal como sostiene Josefina Vásquez, el proceso de inserción en el concierto de las naciones fue difícil, pues al principio era evidente que la independencia se logró consolidar sobre la base de la solidaridad hispanoamericana, pero emergió un celo creciente respecto a los no nativos que se fueron desatando con más fuerza conforme pasaban los años. Los protagonistas de esa primera unidad fueron México y Colombia. Luego, hubo un marcado distanciamiento entre las naciones, debido a las deudas contraídas durante las guerras de independencia, porque era necesario que se definieran las fronteras y porque para tener éxito en sus relaciones comerciales con el mundo, sentían 
que competían entre ellos por mejores condiciones. Todo ello debilitó a cada uno de los países, y en conjunto debilitó a toda la región. El nuevo imperialismo, sustentado en el darwinismo, también hizo lo suyo. En ese sentido, Gran Bretaña, España, Francia y los Estados Unidos aprovecharon la debilidad de los países hispanoamericanos, magnificaron las tensiones entre comerciantes nativos y extranjeros; a partir de ahí protestaron contra el maltrato a sus connacionales. Sus principales medidas de fuerza fueron bloquear los puertos hispanoamericanos, amenazas de bombardeos, invasiones, violaciones a la soberanía costera; todo ello era practicado porque consideraban a las nuevas naciones débiles e inferiores. De todos, fue México el que sufrió en mayor medida y fue la víctima de las mayores amenazas externas. Tuvo intentos de reconquista española, la guerra de Texas, el bloqueo y bombardeo francés, la invasión norteamericana, la intervención francesa. Luego de todo ello, México había perdido la mitad de su territorio. El aprendizaje vino desde un inicio — y a lo largo del siglo XIX_- la necesidad de establecer mecanismos de protección mutua frente al ataque de alguna potencia contra sus territorios. Pero no pudo hacerse realidad dicha unidad, pues cada país estaba enredado en disputas internas que le impedían contar con la estabilidad suficiente como para intentar defenderse de los intereses externos que los amenazaron y que les quitaron sus territorios y recursos (Vásquez 2003a y 2003b).

\subsection{La convocatoria al Congreso de Panamá}

En el caso peruano, y bajo una visión global estratégica, una de las primeras acciones internacionales realizadas durante la etapa bolivariana fue la convocatoria al Congreso de Panamá en 1826. Dicha convocatoria se hizo el 7 de diciembre de 1824 y fue firmada por José Faustino Sánchez Carrión, quien la dirigió a los siguientes Gobiernos: Gran Colombia, México, Río de la Plata y Chile. No dejemos de pensar en la fecha de la convocatoria, pues fue dos días previos a la batalla de Ayacucho, cuando se obtuvo la firma de la capitulación española. ¿Se estaba seguro de un triunfo inminente? ¿Era un plan de contingencia ante un desenlace adverso? Podríamos apostar por lo primero, pues Bolívar tenía bajo su mando un equipo de primer nivel en el campo de batalla y en la administración del país, quienes actuaban estando muy conscientes de la importancia del presente que estaban construyendo cotidianamente y su trascendencia histórica. Como constatamos en las siguientes líneas, en ese entonces, estos hombres se confrontaban con el pasado de la antigüedad clásica, 
y con esa lógica, sabían que las generaciones venideras los rememorarían en momentos críticos similares (De la Reza 2012: 26). La invitación de Sánchez Carrión termina con el siguiente párrafo que expresa lo señalado:

El día que nuestros plenipotenciarios hagan el canje de sus poderes, se fijará en la historia diplomática de la América una época inmortal. Cuando, después de cien siglos, la posteridad busque el origen de nuestro derecho público, y recuerden los pactos que consolidaron su destino, registrará con respeto los protocolos del Istmo: en él encontrará el plan de las primeras alianzas, que trazarán la marcha de nuestras relaciones con el universo. ¿Qué será entonces el Istmo de Corinto, comparado con el de Panamá? (en De la Reza 2010, 42; los énfasis son nuestros).

Podemos apreciar, por lo tanto, que la visión de Bolívar sobre el futuro de Hispanoamérica era de una gran potencia que había logrado unir sus Estados para coordinar acciones de manera confederada. De esa manera superaban la experiencia norteamericana de ser una federación de Estados, y la de los Congresos europeos donde las potencias aseguraban sus intereses. Esa capacidad de coordinar acciones - en igualdad de condiciones y fraternidad - era la fórmula que los habilitaba para ser una potencia de consideración en el concierto internacional.

Meses después también se incluyó entre los invitados a Centroamérica. El lugar que sería la sede de la reunión era el istmo de Panamá. Este fue elegido por estar equidistante y ser céntrico. Es decir, el criterio fue geográfico y tratando de considerar que la distancia sea adecuada para todos. Sin embargo, no se ponderó un criterio fundamental, que era una región insalubre en ese entonces. Asimismo, es menester precisar que, en un principio, no fueron invitados al magno evento los Estados Unidos, Haití ni Brasil. Sin embargo, y en discrepancia con Bolívar, Santander invitó a los Estados Unidos y a Brasil. Bolívar recelaba de ambos, pues eran potencialmente rivales de lo que se proyectaba en el Congreso de Panamá. El primero de ellos por haber proclamado la doctrina Monroe y su afán expansionista sobre México, y el segundo por su condición imperial y porque eso facilitaba mejores relaciones con la Santa Alianza. Bolívar - a diferencia de Santander-; tenía por lo tanto una mirada en política internacional con un enfoque centrado en la geopolítica. Desde ese punto de vista, consideraba un gran aliado a Gran Bretaña, no solo porque era la potencia de ese entonces con gran dominio de los mares, sino también 
porque podría limitar el afán expansionista de los Estados Unidos (De la Reza 2012, 30).

En un principio, los representantes plenipotenciarios del Perú fueron Manuel Lorenzo de Vidaurre y José María de Pando; luego este último fue reemplazado por Manuel Pérez de Tudela. Vale la pena precisar que tanto el Perú como Colombia fueron los países que hicieron la convocatoria.

Este congreso - de iniciativa de Simón Bolívar - estaba inspirado en los congresos que las potencias europeas realizaban desde 1815 - ya mencionados- - pero a diferencia de la agenda que trataban ellos como en el Congreso de Viena, la versión latinoamericana tenía por objetivo abordar — en un plano de igualdad - principios de solidaridad y seguridad colectiva respecto a la defensa común. Porras sostiene que, ya en la Carta de Jamaica (1815), Bolívar planteó una propuesta que vincule a todo el nuevo mundo; tres años después propone al director supremo de las Provincias Unidas del Río de la Plata la constitución de una gran federación americana (Porras 1926, VIII). Fue así como — siguiendo a Boersner-, a partir de 1821, Bolívar inicia dichas gestiones a través del canciller de Colombia, Pedro Gual, quien propone la creación de una confederación como la Santa Alianza, que sería una «verdadera sociedad de naciones hermanas». Por ello es Colombia la primera de las naciones en tener la iniciativa de la firma de tratados con los países hermanos. Dos años después, ante las intenciones de la Santa Alianza de intervenir militarmente a la región, se vuelve a convocar un congreso a reunirse en Panamá, solicitando que cada país envíe dos representantes plenipotenciarios. Cuatro fueron los temas a ser abordados: i) alianza y confederación perpetua de los Estados americanos; ii) delimitaciones territoriales sobre la base del uti possidetis de 1810; iii) respeto a la soberanía de cada parte contratante; iv) no intervención (Boersner 1982, 107).

La propuesta de Bolívar residía en el diseño de un federalismo continental. Es decir, países libres y soberanos debían coordinar sus acciones entre ellos y con el resto del mundo, especialmente con las potencias Gran Bretaña y Francia. Debían tener cuidado de los Estados Unidos y estar a buen recaudo de la Santa Alianza. De esa manera podían salir al concierto internacional más fuertes que si lo hicieran uno por uno. En ese momento se planteaban que esa opción confederativa les daría mejores opciones frente a la avidez y expectativas que tenían las potencias de hacer comercio preferente en aquellos lugares que habían sido monopolio de la monarquía española. Un aspecto particularmente importante que destaca John Lynch respecto a esta visión supranacio- 
nal de Bolívar se refiere a que el Libertador daba por sentada la existencia de las naciones individuales, y al parecer, ahí estuvo la principal limitación. Es que su proyecto apuntaba a fortalecer — no crear — la nación, hacerla económicamente viable y de una dimensión suficiente como para ganarse el respeto de las expectantes potencias (Lynch 2006, 284-291). El propio Bolívar lo expresó así a inicios de 1826: el Congreso de Panamá sería incluso más grande y poderoso que la Santa Alianza, se trataba de una iniciativa diseñada para que ganen todos los miembros parte, incluyendo en dicho proyecto a la Gran Bretaña (Bolívar 1826, 260-261).

\subsection{El desarrollo del Congreso de Panamá}

El Congreso de Panamá duró alrededor de tres semanas — del 22 de junio al 15 de julio de 1826 - y congregó a la Gran Colombia, el Perú (incluida Bolivia), México y Centroamérica, cada uno con dos representantes plenipotenciarios. Asimismo, fueron invitados representantes de los Estados Unidos, Gran Bretaña y Países Bajos. La asistencia se dio de la siguiente manera, como se muestra en la tabla 3:

TABLA 3

Países y representantes en el Congreso de Panamá

\begin{tabular}{|c|c|c|c|c|c|}
\hline Ord. & País & $\begin{array}{c}\text { Tipo de } \\
\text { participación }\end{array}$ & $\begin{array}{l}\text { Nombre del } \\
\text { representante }\end{array}$ & $\begin{array}{l}\text { Nombre del } \\
\text { representante }\end{array}$ & Observaciones \\
\hline 1 & Colombia & Miembro & Pedro Gual & $\begin{array}{l}\text { Pedro Briceño } \\
\text { Méndez }\end{array}$ & \\
\hline 2 & Guatemala & Miembro & Antonio Larrazábal & Pedro Molina & \\
\hline 3 & México & Miembro & $\begin{array}{l}\text { José Mariano } \\
\text { Michelena }\end{array}$ & $\begin{array}{l}\text { José Domínguez } \\
\text { Manso }\end{array}$ & \\
\hline 4 & Perú & Miembro & $\begin{array}{l}\text { Manuel Lorenzo de } \\
\text { Vidaurre }\end{array}$ & $\begin{array}{l}\text { José María } \\
\text { de Pando. } \\
\text { Reemplazado } \\
\text { por Manuel } \\
\text { Pérez de Tudela. }\end{array}$ & $\begin{array}{l}\text { No } \\
\text { participaron en } \\
\text { Tacubaya. }\end{array}$ \\
\hline 5 & Gran Bretaña & Invitado & Eduardo Dawkins & & \\
\hline 6 & Países Bajos & Invitado & Jan Verveer & & \\
\hline 7 & $\begin{array}{l}\text { Estados } \\
\text { Unidos }\end{array}$ & Invitado & John Sergeant & & $\begin{array}{l}\text { Solo estuvo en } \\
\text { Tacubaya. }\end{array}$ \\
\hline
\end{tabular}

Fuente: Tudela (2016) 
En el caso peruano, los representantes recibieron hasta tres instrucciones. Nótese que la representación para este Congreso podría interpretarse bajo la fórmula de «mandato imperativo», pues recibían instrucciones de sus respectivos Gobiernos y por lo tanto estaban sujetos a ellas. Si seguimos a Guerra, las primeras instrucciones fueron dadas a Vidaurre y a Pando por el general colombiano Tomás Heres el 15 de mayo de 1825, y por lo tanto el principal objetivo era afirmar el predominio colombiano en la dirección de la asamblea y en los fundamentos para la fijación de límites. Las segundas instrucciones fueron enviadas el 18 de febrero de 1826 por Hipólito Unanue, en ese entonces a cargo del Ministerio de Relaciones Exteriores. En estas segundas instrucciones se puede apreciar que hay un giro hacia una mayor moderación respecto a la situación de Cuba y Puerto Rico y a la esclavitud, manteniendo la misma línea respecto a las negociaciones con España. Las últimas instrucciones del 25 de mayo de 1826 fueron dadas por José María de Pando, a la sazón ministro de Relaciones Exteriores; en estas instrucciones se expresan los cambios de ese momento respecto a la coyuntura histórica, al liderazgo de Bolívar, entre otros puntos clave (Guerra 2016, 122-123; De la Reza 2012; Buller 2021).

Resultado de ello se firmó un Tratado de Unión, Liga y Confederación Perpetua, dos conciertos y una convención de contingentes; los tres últimos eran precisiones al tratado. Dichos acuerdos eran para ser aplicados en épocas de guerra y de paz. Su objetivo era sostener y defender la soberanía e independencia de las partes, mantener la paz y auxiliarse mutuamente en caso de agresión. En periodo de guerra podían transitar libremente los ejércitos y barcos de los países aliados. Asimismo, cada país no debía firmar la paz de manera separada, sino que sería de común acuerdo con los demás. Finalmente, debían desarrollar conjuntamente su comercio y bienestar mutuos. En ese mismo sentido, acordaron reunirse con una frecuencia bianual. No obstante, al no recibir la ratificación de sus respectivos países y no continuar la reunión en Tacubaya, prácticamente dejó de tener efecto práctico. Solo Colombia ratificó las convenciones en 1827, el Perú no lo hizo porque en ese periodo Bolívar había dejado de tener influencia política y había una fuerte corriente en su contra. En el caso de México, había sospechas y rivalidades entre los Gobiernos por supuestas pretensiones hegemónicas de unos y otros: 
[...] el enviado mexicano opinaba que la convocatoria para la Asamblea de Panamá había tenido el gran mérito de inaugurar las relaciones internacionales en el ámbito iberoamericano, pues gracias a ella los diversos gobiernos interesados en participar habían entrado más o menos directamente en contacto para ocuparse de asuntos que iban más allá de las misiones de reconocimiento en Londres o, en menor medida, en Washington.

Sin embargo, eran relaciones que se iniciaban bajo el signo de la desconfianza, la rivalidad y la búsqueda de balances de poder regional y geopolítico; y la Gran Colombia, por su activo papel en la organización de la Asamblea, se presentaba ya con una preeminencia incómoda, al pretender aparecer «como la primera de las nuevas repúblicas». El bosquejo inicial de alianzas y rivalidades regionales pintado por Torrens ponía naturalmente a Perú a las órdenes de Colombia por la «deuda» contraída con Bolívar en virtud de la liberación del antiguo virreinato, país del que ahora el Libertador era presidente perpetuo. Torrens suponía que Chile podía aliarse con México para compensar el apoyo de Guatemala a Colombia (que hacía frontera con Costa Rica), pues los dirigentes del país austral resentían que Bolívar les hubiera arrebatado de las manos «la Gloria de liberar al Perú». Por su parte, Colombia y Buenos Aires ya se miraban con antipatía por la negativa del gobierno porteño a participar en un proyecto de confederación, al que veía como una maniobra del Libertador para implantar su dominio sobre el resto de los antiguos territorios españoles en América (Palacios y Covarrubias 2011, 53).

Hacia el final de la década de 1820, el Congreso de Panamá era visto como una de las últimas utopías de Bolívar: la Gran Colombia se había desestructurado, la Federación de los Andes era poco menos que un sueño y la Federación Centroamericana había dejado de funcionar, por lo que las opciones de hacerse fuertes a través de alianzas supranacionales para hacer frente al concierto de naciones fueron sobrepasadas por el contexto, la debilidad y las luchas internas en cada uno de los países. De esa manera, Boersner sostiene que en el hemisferio occidental se plasmaron dos esquemas de convivencia y organización internacional: el primero denominado la «doctrina de Monroe» y el segundo, la iniciativa de Simón Bolívar de conformar un Tratado de Unión, Liga y Confederación Perpetua (Boersner 1982, 110-111). Ambas completamente distintas entre sí. La primera quedó como una espada de Damocles para la soberanía de cada país y la otra perduró en la memoria como una promesa futura. 


\section{Conclusiones}

En todo este periodo, el Perú se caracterizó por ser un Estado de baja capacidad que comenzó a mejorar a partir de la década de 1840 con los ingresos del guano, pero con la guerra del Pacífico nuevamente el Estado colapsó. En ese entonces, el Estado pudo desarrollar relaciones exteriores, las que estuvieron a cargo de personas notables como José Faustino Sánchez Carrión, Hipólito Unanue y José María de Pando, entre otros. En esos primeros años se delinean principios básicos en la política internacional como la no injerencia en los asuntos internos de los países, neutralidad y sometimiento al derecho. La inestabilidad política del siglo XIX dio lugar a cinco coyunturas críticas que se expresaron en el caso del Ministerio de Relaciones Exteriores en el número elevado de ministros (casi dos por año) y que algunos de ellos tuvieron que asumir dicha responsabilidad en varias oportunidades.

El proceso de configuración de la nación fue producto del proceso independentista, y este implicó la conformación de círculos concéntricos. Esta dinámica dará lugar a la producción de tres momentos clave: i) ruptura con la monarquía española con quienes se compartían creencias, cultura y sentidos de pertenencia; ii) conformación de una identidad americana que dio lugar a que se formen ejércitos americanos que participaron de manera fraterna en conseguir la independencia de cada país, este espíritu fraterno duró hasta finales de la década de 1820, especialmente hasta el Congreso de Panamá; iii) luego llegaron las tensiones y los conflictos que muchas veces derivaron en guerras. Los primeros reconocimientos se dieron de los países de la región y la demora en dicho reconocimiento de debió al caso español, ocurrido recién en 1879.

El Perú participó en el proceso de reconocimiento de las repúblicas hispanoamericanas como parte del complejo proceso de la independencia de España. Primero se dio el reconocimiento entre los países de la región, con la firma de tratados y la expectativa de formar federaciones o instancias supranacionales que facilitasen el reconocimiento de las potencias y mejores condiciones políticas y económicas. Asimismo, la idea de abarcar varios territorios y lograr federaciones y confederaciones estaba pensada como una estrategia de defensa y seguridad frente a posibles invasiones. Por eso los objetivos del Congreso de Panamá no pudieron plasmarse, pero quedó como un deseo futuro. 
En este periodo de bicentenario de la proclamación de la independencia de Lima, podemos reflexionar sobre la trayectoria hacia el reconocimiento. El Perú en la primera hora - tal como sostiene Porras - tuvo una vocación fraternal y solidaria, pues en su territorio se había sellado — en gran parte — la independencia de América Latina. Así lo demuestra la comunicación que remitieron nuestros primeros ministros de Relaciones Exteriores. Pero el reconocimiento tuvo una trayectoria compleja y sinuosa, pues España llevó a cabo esa acción formal recién durante la segunda mitad del siglo, en el mismo año que empezó la guerra con Chile. Durante todo ese periodo, el contexto interno de coyuntura crítica e inestabilidad política y el contexto externo de un orden internacional conservador pueden explicar esa demora y complejidad. 


\section{Referencias bibliográficas}

Acemoglu, D. y Robinson, J. 2012. Por qué fracasan los países. Los orígenes del poder, la prosperidad y la pobreza. Bogotá: Grupo Planeta.

Aljovín, C. y Velásquez, D. 2014. Perú en el mundo. En Contreras, C. (Coord.). Perú. La construcción nacional (pp. 101-162). América Latina en la historia contemporánea, 1830-1880 (tomo 2). Madrid: Fundación Mapfre, Taurus.

Aljovín, C. y Chávez, F. 2012. Perú. En Malamud, C. (Coord.). Ruptura y reconciliación. España y el reconocimiento de las independencias latinoamericanas. América Latina en la historia contemporánea. Serie Recorridos 1. Madrid: Fundación Mapfre, Taurus.

Anna, T. 2003. La caída del gobierno español en el Perú. El dilema de la independencia. Lima: Instituto de Estudios Peruanos.

Anderson, B. 1997. Comunidades imaginadas. Reflexiones sobre el origen y la difusión del nacionalismo. Ciudad de México: Fondo de Cultura Económica.

Bello, A. 2003 (1832). Principios del derecho de jentes. Buenos Aires: Biblioteca Virtual Universal. https://biblioteca.org.ar/libros/71387.pdf

Boersner, D. 1982. Capítulo III. La transición independentista (1790-1828), Capítulo IV. Consolidación de naciones y hegemonía comercial inglesa (1828-1852). En Relaciones internacionales de América Latina. Ciudad de México: Editorial Nueva Imagen.

Bolívar, S. 2009 (1805-1830). Doctrina del Libertador. Pérez, M. (Comp.). Notas y cronología. Caracas: Biblioteca Ayacucho.

Buller, C. 2021. Los desafíos de la Independencia y la construcción de la política exterior del Perú». En O’Phelan, S. (Comp.). La independencia del Perú. De los borbones a Bolivar. Lima: Banco Central de Reservas del Perú.

Bushnell, D. 2010. Colombia en el mundo. En Posada, E. (Dir.). Colombia. Crisis imperial e independencia. América Latina en la historia contemporánea, 1808-1830 (tomo 1). Lima: Fundación Mapfre, Taurus.

Casalino, C. 2021. Representación política en un contexto de transición. Análisis del caso de Raúl Porras Barrenechea como senador en el Congreso Peruano (1956-1958). RIRA, 6(2), 199-238.

Casalino, C. 2020a. José Hipólito Unanue Pavón. Un presidente amante del país. En De la Guerra, J. (Coord.). Presidentes y gobernantes del Perú republicano. Lima: Municipalidad de Lima.

Casalino, C. 2020b. El padrón electoral como expresión de las disputas por el poder a lo largo de la historia republicana (Perú: 1821-2019). En Sánchez, M. y Valenzuela, M. 
(Eds.). Democracia, participación y representación electoral en el Perú. Textos para reflexionar el Estado en los siglos XX y XXI. Lima: ONPE.

Casalino, C. (Comp.). 1999. Raúl Porras Barrenechea, parlamentario. Lima: Biblioteca del Congreso del Perú.

Castillo, M., Toussaint, M. y Vásquez, M. 2011. Historia de las relaciones internacionales de México, 1821-2010. Centroamérica (volumen II). Ciudad de México: Secretaría de Relaciones Exteriores.

Chang, A. 2013. Entre la espada y la pared. La administración del Gral. Juan Antonio Pezet frente a la crisis diplomática con España (1863-1865) (tesis de licenciatura). Lima: Universidad Nacional Mayor de San Marcos.

Chust, M. y Rosas, C. (Eds.). 2017. El Perú en Revolución. Independencia y guerra: un proceso, 1780-1826. Casteló de la Plana: El Colegio de Michoacán, Universitat Jaume I, Pontificia Universidad Católica del Perú.

Dager, J. 2006. Periodo 1801-1825. En Del Busto, J. A. (Dir). Historia cronológica del Perú. Lima: PetroPerú.

De la Torre, R. 2015. El Congreso de Viena (1814-1815). Madrid: Universidad Complutense, Catarata.

Demélas, M. 2003. La invención politica. Bolivia, Ecuador, Perú en el siglo XIX. Lima: IFEA, Instituto de Estudios Peruanos.

Estenssoro, J. C. y Méndez, C. (Eds.). 2021. Las independencias antes de la independencia: miradas alternativas desde los pueblos. Lima: IFEA, Instituto de Estudios Peruanos.

Fisher, J. 2000. El Perú borbónico 1750-1824. Lima: Instituto de Estudios Peruanos.

Guerra, M. 2016. Manuel Pérez de Tudela: el republicano. Lima: Instituto de Estudios Peruanos, Fondo Editorial del Congreso del Perú.

Hernández, E. 2019. José de la Riva Agüero y Sánchez Boquete (1783-1858). Primer presidente del Perú. Lima: Fondo Editorial del Congreso del Perú, Pontificia Universidad Católica del Perú.

Hernández, E. 2018. Bolívar y la Iglesia en el Perú: la cuestión del Patronato. Anuario de Historia de la Iglesia, 27, 225-246.

Lynch, J. 2009. San Martín. Soldado argentino, héroe americano. Barcelona: Editorial Crítica.

Lynch, J. 2006. Simón Bolívar. Barcelona: Editorial Crítica.

Monteagudo, B. 1979 (1825). Sobre la necesidad de una federación general entre los Estados hispanoamericanos. Ciudad de México: Universidad Autónoma de México.

Novak, F. y Namihas, S. 2020. El bicentenario de la política exterior peruana y su proyección en un mundo de cambios. Lima: IDEI, Konrad Adenauer Stiftung. 
Novak, F. y Namihas, S. 2013. Las relaciones entre el Perú y Bolivia (1826-2013). Lima: IDEI, Pontificia Universidad Católica del Perú, Konrad Adenauer Stiftung.

Novak, F. y Namihas, S. 2012. Las relaciones entre el Perú y Brasil (1826-2012). Lima: IDEI, Pontificia Universidad Católica del Perú, Konrad Adenauer Stiftung.

Novak, F. 2001. Las relaciones entre el Perú y España (1821-2000). Lima: IDEI, Pontificia Universidad Católica del Perú.

O’Phelan, S. (Comp). 2021. La independencia del Perú. De los borbones a Bolívar. Lima: Banco Central de Reservas del Perú.

O’Phelan, S. 2019. Simón Bolivar y la conclusión de la Independencia en el suelo de los Incas. Lima: Fondo Editorial del Congreso del Perú.

O’Phelan, S. y Lomné, G. 2013. Abascal y la contra independencia de América del Sur. Lima: IFEA, Pontificia Universidad Católica del Perú.

Palacios, G. y Covarrubias, A. 2011. América del Sur. En De Vega, M. (Coord.). Historia de las relaciones internacionales de México, 1821-2010 (volumen 4). Ciudad de México: Secretaría de Relaciones Exteriores.

Pando, J. 1852. Elementos del Derecho Internacional. Madrid: Imprenta de J. Martín Alegría.

Pereira, J. C. 1992. España e Iberoamérica: un siglo de relaciones (1836-1936). Mélanges de la Casa de Velásquez, 28-3, 97-127.

Pereyra, H. 2014. La independencia del Perú: ¿guerra colonial o guerra civil? Una aproximación desde la teoría de las Relaciones Internacionales. Madrid: CEXECI. Centro Extremeño de Estudios, Cooperación con Iberoamérica.

Pereyra, H. 2013. El Perú en el mundo. En O'Phelan, S. (Coord.). Perú. Crisis imperial e independencia. América Latina en la historia contemporánea (1808-1830) (tomo 1). Madrid: Fundación Mapfre, Taurus.

Pino, E. 2021. Bolívar en el Perú. En Varón, R. y Guzmán, D. (Eds.). La Independencia. Bicentenario del Perú. Lima: MNAAHP.

Porras, R. 2011 (1930). Historia de los límites del Perú. Lima: Fundación M. J. Bustamante de la Fuente.

Porras, R. (Comp.) 1926. El Congreso de Panamá (1826). Lima: Imprenta «La opinión nacional»

Portillo, J. 2010. España en el mundo. En Chust, M. (Coord.). España. Crisis imperial e independencia (pp. 107-165). América Latina en la historia contemporánea, 18081830 (tomo 1). Lima: Fundación Mapfre, Taurus.

Quijada, M. 2003. ¿Qué nación? Dinámicas y dicotomías de la nación en el imaginario hispanoamericano. En Annino, A. y Guerra, F. (Coords.). Inventando la na- 
ción. Iberoamérica. Siglo XIX (pp. 287-315). Ciudad de México: Fondo de Cultura Económica.

Quiroz, A. 2013. Historia de la corrupción en el Perú. Lima: Instituto de Estudios Peruanos, Instituto de Defensa Legal.

Reza, G. de la 2014. ¿Necesidad o virtud? Razones y alcances de los tratados continentales hispanoamericanos de 1856. Histórica XXXVIII, 61-83.

Reza, G. de la. 2012. El ciclo confederativo: historia de la integración latinoamericana en el siglo XIX. Lima: Fondo Editorial de la Universidad Nacional Mayor de San Marcos.

Reza, G. de la (Comp.). 2010. Documentos sobre el Congreso Anfictiónico de Panamá. Caracas: Biblioteca Ayacucho.

Reza, G. de la 2006. El Congreso de Panamá de 1826 y otros ensayos de integración latinoamericana en el siglo XIX. Ciudad de México: Universidad Autónoma Metropolitana Azcapotzalco.

Reza, G. de la 2003. El Congreso Anfictiónico de Panamá. Una hipótesis complementaria sobre el fracaso del primer ensayo de integración latinoamericana. Araucaria, (10), 188-214.

Rojas, R. 2017. La república imaginada. Representaciones culturales y discursos politicos en la época de la Independencia. Lima: Instituto de Estudios Peruanos.

Silva, J. 2018 (1858). Curso de derecho internacional o de gentes. Lima: Centro de Estudios Constitucionales, Tribunal Constitucional del Perú.

Sobrevilla, N. 2021. Independencia. A 200 años de lucha por la libertad. Lima: Penguin Random House.

Tilly, Ch. 2010. Democracia. Madrid: Akal.

Vásquez, J. 2003a. Una difícil inserción en el concierto de las naciones. En Annino, A. y Guerra, F. (Coords.). Inventando la nación. Iberoamérica. Siglo XIX. Ciudad de México: Fondo de Cultura Económica.

Vásquez, J. 2003b. La inserción de los nuevos Estados en el orden internacional. En Vásquez, J. (Dir.). La construcción de las naciones latinoamericanas, 1820-1870 (pp. 483-499). Madrid: Ediciones Unesco, Editorial Trotta.

Vásquez, J. 2003c. Relaciones interamericanas e intervencionismo. En Vásquez, J. (Dir.). La construcción de las naciones latinoamericanas, 1820-1870 (pp. 501-522). Madrid: Ediciones Unesco, Editorial Trotta.

Zuloaga, M. 2021. Las luchas por la Independencia (1780-1830). Lima: Instituto de Estudios Peruanos. 